\title{
Thymine DNA glycosylase as a novel target for melanoma
}

\author{
Pietro Mancuso $0^{1,2,3} \cdot$ Rossella Tricarico $^{1} \cdot$ Vikram Bhattacharjee $^{4} \cdot$ Laura Cosentino $^{1} \cdot$ Yuwaraj Kadariya $^{4}$. \\ Jaroslav Jelinek ${ }^{5} \cdot$ Emmanuelle Nicolas $^{1} \cdot$ Margret Einarson $^{1} \cdot$ Neil Beeharry ${ }^{4} \cdot$ Karthik Devarajan $^{6} \cdot$ Richard A. Katz $^{1}$. \\ Dorjbal G. Dorjsuren ${ }^{7}$ Hongmao Sun ${ }^{7}$ Anton Simeonov ${ }^{7}$ - Antonio Giordano ${ }^{2,8}$ - Joseph R. Testa $\mathbb{1}^{4}$. \\ Guillaume Davidson $^{9} \cdot$ Irwin Davidson $^{9,10} \cdot$ Lionel Larue $^{3,10,11} \cdot$ Robert W. Sobol $^{12} \cdot$ Timothy J. Yen $^{4}$. \\ Alfonso Bellacosa ${ }^{1}$
}

Received: 24 February 2018 / Revised: 8 November 2018 / Accepted: 4 December 2018 / Published online: 23 January 2019

(c) The Author(s) 2019. This article is published with open access

\begin{abstract}
Melanoma is an aggressive neoplasm with increasing incidence that is classified by the NCI as a recalcitrant cancer, i.e., a cancer with poor prognosis, lacking progress in diagnosis and treatment. In addition to conventional therapy, melanoma treatment is currently based on targeting the BRAF/MEK/ERK signaling pathway and immune checkpoints. As drug resistance remains a major obstacle to treatment success, advanced therapeutic approaches based on novel targets are still urgently needed. We reasoned that the base excision repair enzyme thymine DNA glycosylase (TDG) could be such a target for its dual role in safeguarding the genome and the epigenome, by performing the last of the multiple steps in DNA demethylation. Here we show that $T D G$ knockdown in melanoma cell lines causes cell cycle arrest, senescence, and death by mitotic alterations; alters the transcriptome and methylome; and impairs xenograft tumor formation. Importantly, untransformed melanocytes are minimally affected by $T D G$ knockdown, and adult mice with conditional knockout of $T d g$ are viable. Candidate TDG inhibitors, identified through a high-throughput fluorescence-based screen, reduced viability and clonogenic capacity of melanoma cell lines and increased cellular levels of 5-carboxylcytosine, the last intermediate in DNA demethylation, indicating successful on-target activity. These findings suggest that TDG may provide critical functions specific to cancer cells that make it a highly suitable anti-melanoma drug target. By potentially disrupting both DNA repair and the epigenetic state, targeting TDG may represent a completely new approach to melanoma therapy.
\end{abstract}

These authors contributed equally: Pietro Mancuso, Rossella Tricarico

Supplementary information The online version of this article (https:// doi.org/10.1038/s41388-018-0640-2) contains supplementary material, which is available to authorized users.

Alfonso Bellacosa

Alfonso.Bellacosa@fccc.edu

1 Cancer Epigenetics Program, Fox Chase Cancer Center, 333 Cottman Avenue, Philadelphia, PA 19111, USA

2 Department of Medical Biotechnologies, Universita' degli Studi di Siena, Siena, Italy

3 Institut Curie, PSL Research University, INSERM U1021, Normal and Pathological Development of Melanocytes, 91405 Orsay, France

4 Cancer Biology Program, Fox Chase Cancer Center, 333 Cottman Avenue, Philadelphia, PA 19111, USA

5 Fels Institute for Cancer and Molecular Biology, Temple University School of Medicine, Philadelphia, PA 19140, USA

6 Department of Biostatistics, Fox Chase Cancer Center, 333

\section{Introduction}

Melanoma is an aggressive cancer, whose incidence has increased over the past two decades in Western countries

Cottman Avenue, Philadelphia, PA 19111, USA

7 Division of Preclinical Innovation, National Center for Advancing Translational Sciences, National Institutes of Health,

Rockville, MD 20850, USA

8 Sbarro Institute for Cancer Research and Molecular Medicine, Department of Biology, College of Science and Technology, Temple University, Philadelphia, PA 19122, USA

9 Institut de Génétique et de Biologie Moléculaire et Cellulaire, CNRS/INSERM/ULP, 67404 Illkirch, France

10 Equipe Labellisée Ligue Contre le Cancer, Orsay, France

11 University Paris-Sud, University Paris-Saclay, CNRS UMR3347, Orsay, France

12 Department of Oncologic Sciences, Mitchell Cancer Institute, University of South Alabama, Mobile, AL 36604, USA 
[1]. Although the majority of melanoma cases are cured after surgical excision of the primary tumor, the metastatic form of the disease has poor prognosis, being highly resistant to therapy. Targeted therapy directed against $B R A F$ is effective but short-lived, because resistance develops rapidly. More recently, immunotherapy based on checkpoint inhibition demonstrated responses in $\sim 60 \%$ of advanced melanoma patients, but a large fraction of patients is refractory. Thus advanced therapeutic strategies based on novel targets are urgently needed.

We recently identified the requirement of the base excision repair enzyme thymine DNA glycosylase (TDG) for mammalian development and specifically for development of the neural crest, precursor of melanocytes [2]. This requirement is due to the unique dual role of TDG in safeguarding genome and epigenome [3, 4]. TDG not only protects $\mathrm{CpG}$ sites from spontaneous deamination of 5methylcytosine $(5 \mathrm{mC})$ and cytosine, thus avoiding $\mathrm{C}>\mathrm{T}$ transition mutations, but importantly, at the epigenomic level, is involved in active DNA demethylation downstream of the ten-eleven translocation (TET) dioxygenases [2-6].

Active DNA demethylation involves the iterative oxidation of $5 \mathrm{mC}$ by TET1-3 to produce the novel cytosine species 5-hydroxymethylcytosine (5hmC), 5formylcytosine (5fC), and 5-carboxylxytosine (5caC), followed by TDG-mediated removal of $5 \mathrm{fC}$ and $5 \mathrm{caC}$ [7, 8]. In this pathway, isocitrate dehydrogenase (IDH) generates $\alpha$-ketoglutarate, a cofactor for TET-mediated oxidation.

Alterations of DNA demethylation, through mutations/ reduced expression of IDH2 and TET family genes, have been described in melanoma and correlated with worse prognosis [9-15]. Moreover, decreased levels of 5hmC have been reported in melanoma and represent a novel epigenetic biomarker with diagnostic/prognostic implications [16, 17].

Given the importance of DNA demethylation in melanomagenesis and TDG requirement for neural crest development [2], we began exploring the role of TDG in melanoma. We reasoned that the two non-redundant (genomic and epigenomic) functions of TDG may represent a vulnerability of tumor cells that can be exploited as novel targets for treatment, because targeting TDG may have the double effect of altering DNA repair capacity and epigenetic state. In this study, through cell culture and mouse xenograft studies, we establish the importance of TDG in maintaining the viability of melanoma cells, and using a DNA repair molecular beacon assay [18], we isolate first-generation TDG inhibitors and characterize their anticancer activity.

\section{Results}

\section{TDG is expressed in melanoma, and its knockdown induces morphological changes in melanoma cell lines}

Examination of the Oncomine database (http://www. oncomine.org) revealed that the median expression levels of $T D G$ mRNA are similar in melanoma samples and melanocytic nevi (levels are higher in normal skin, in which, however, the melanocytes are a minority) (Fig. 1a). In the Human Protein Atlas database, nuclear expression of TDG protein is also maintained at high-to-medium levels in melanomas; and high expression is associated with unfavorable prognosis (Suppl. Figure 1a; http://www.proteinatla s.org). Interestingly, in TCGA-SKCM (skin cutaneous melanoma) cases, there is a positive correlation between TDG and TET1-3 mRNA expression levels (Suppl. Figure 1b). These observations were consistent with the possibility that TDG is a melanoma target and prompted us to examine the consequences of its knockdown.

TDG protein and mRNA are expressed in a panel of melanoma lines, at levels varying from low to high, and apparently inversely correlating with tumorigenic potential (Suppl. Figure 2). TDG mRNA and protein expression is also maintained in normal melanocyte cultures at levels similar to melanoma cell lines (Suppl. Figure 2) [19]. We used the C8 lentivirus expressing an short hairpin RNA (shRNA) against TDG [2] to knock down the TDG expression in Mel501, Mull, and SK28 melanoma lines (Fig. 1b). TDG knockdown induced marked morphological changes in all three cell lines (large, flat, multinucleated cells bearing numerous and long dendritic processes) (Fig. 1c-e and Suppl. Figure 3). Similar morphological changes were also observed in other melanoma cell lines (Rosi and MNT-1, Suppl. Figure 4a). Similar results were obtained with a second $T D G$ shRNA lentivirus, sh4575, targeting a different region of $T D G$ (Suppl. Figure $4 \mathrm{~b}-\mathrm{c}$ ), which rules out off-target effects. The on-target knockdown efficiency of $\mathrm{C} 8$ and sh4575 were confirmed not only by the reduction of TDG protein levels but also by the expected increase of $5 \mathrm{caC}$ levels (Fig. 1f and Suppl. Figure 4d).

\section{TDG knockdown reduces proliferation and induces cell cycle arrest and multinucleation}

Morphological changes were associated with decreased proliferation of Mel501, Mull, and SK28 melanoma lines. To elucidate the mechanism by which $T D G$ knockdown reduces cell proliferation, we analyzed the cell cycle profile of parental, shC8-, and pLKO-infected Mel501, Mull, and 

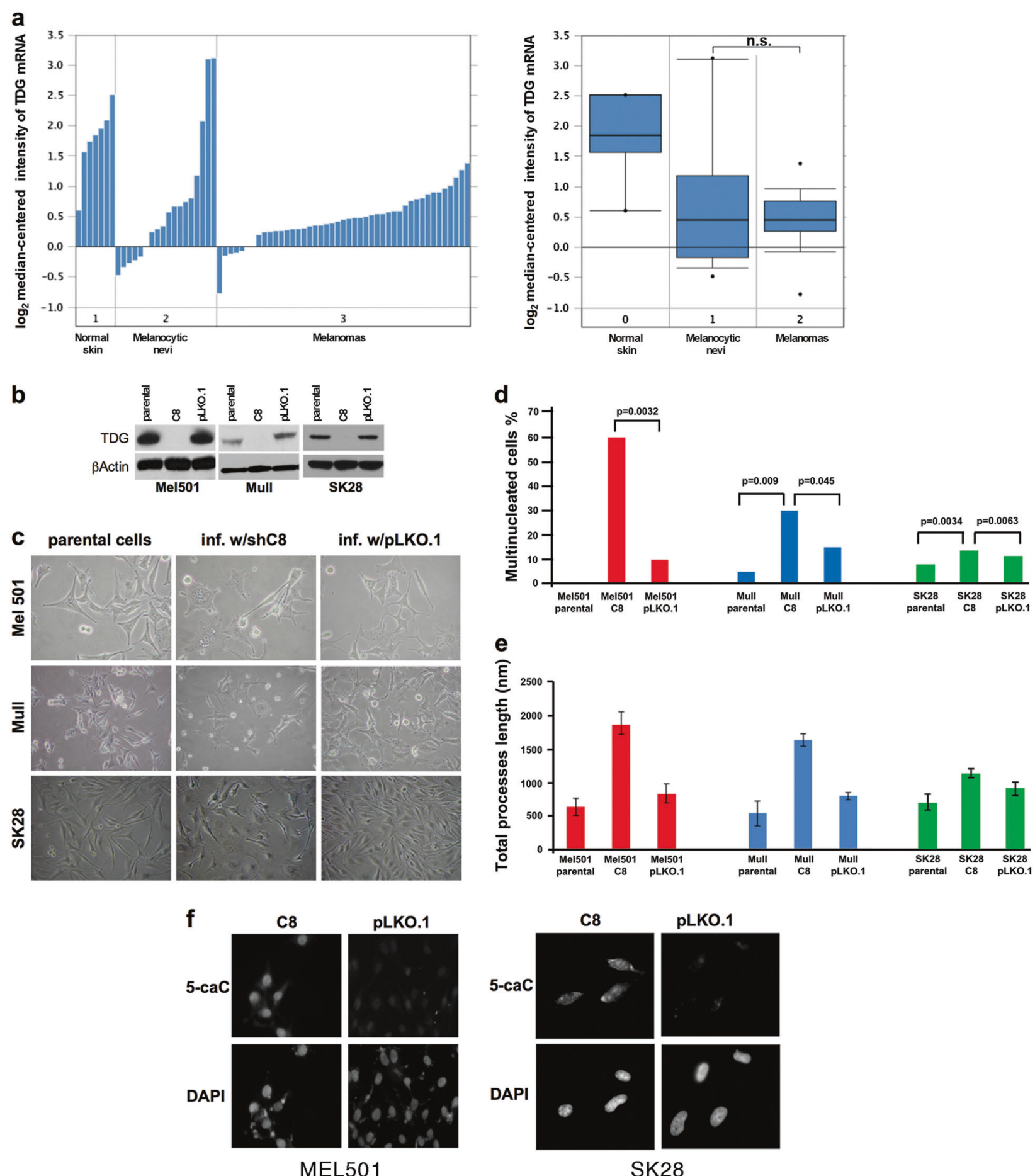

MEL501

Fig. $1 T D G$ knockdown induces morphological changes in melanoma cells. a Expression levels of $T D G$ mRNA in normal human skin, melanocytic nevi, and cutaneous melanoma in Talantov melanoma dataset (Oncomine); both individual and boxplot representations are shown. The difference between the median TDG expression in melanocytic nevi and melanoma samples is not significant (n.s.) by Wilcoxon rank-sum test. b Western blot showing effective TDG knockdown in Mel501, Mull, and SK28 cells in comparison to parental and control pLKO.1-infected cells 3 days after infection. $\mathbf{c}$ Phasecontrast images of parental, TDG knockdown (C8), and control

pLKO.1-infected Mel501, Mull, and SK28 cells. d Percentage of multinucleated cells and e total length of cellular processes in parental, $T D G$ knockdown (C8), and control pLKO.1-infected Mel501, Mull, and SK28 cells. Data are presented as average \pm standard deviation (SD). f Immunofluorescence staining for 5-carboxylcytosine (5caC) in $T D G$ knockdown and control pLKO.1-infected Mel501 and SK28 cells. Nuclei are counter-stained with DAPI. P parental cells, C8 short hairpin RNA (shRNA) lentivirus against $T D G$, pLKO.1 lentivirus vector control 
a
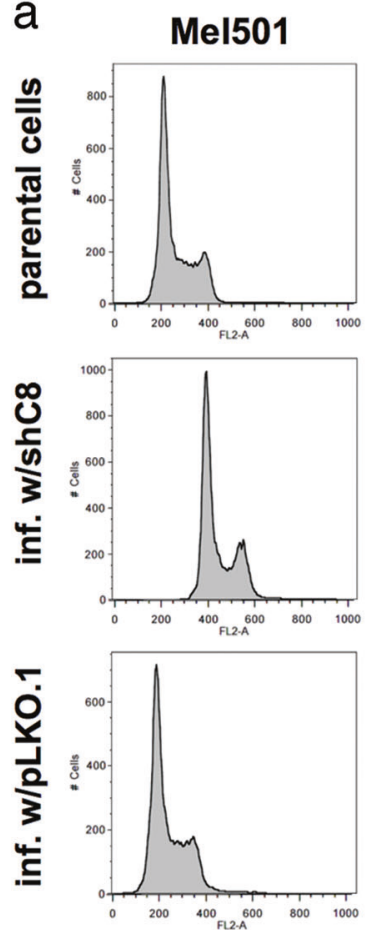

Mull
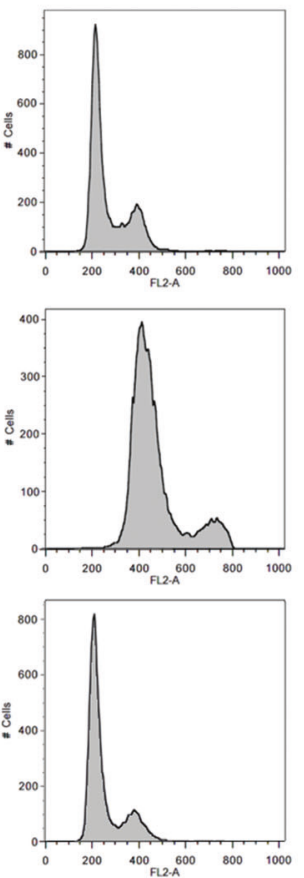

SK28
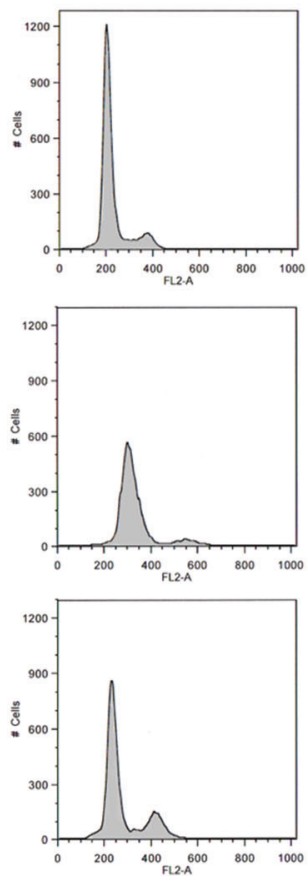

b

\begin{tabular}{|l|r|r|r|r|}
\hline & G1 & $\mathbf{S}$ & G2-M & $>\mathbf{4 n}$ \\
\hline MEL501 parental & 46.8 & 33.8 & 14.3 & 0.8 \\
\hline MEL501 C8 & 0 & 1 & 49.8 & 47.1 \\
\hline MEL501 pLKO & 44.2 & 35.7 & 13.8 & 1.6 \\
\hline \multicolumn{5}{|c|}{} \\
\hline Mull parental & 64.1 & 9.5 & 20.2 & 4.6 \\
\hline Mull C8 & 0 & 1.7 & 71.4 & 18.5 \\
\hline Mull pLKO & 68.4 & 6.7 & 16.2 & 5.1 \\
\hline \multicolumn{5}{|c|}{} \\
\hline SK28 parental & 74.9 & 4.6 & 15.2 & 4.8 \\
\hline SK28 C8 & 2.7 & 67 & 15.9 & 14.1 \\
\hline SK28 pLKO & 71 & 6.9 & 17.7 & 4.3 \\
\hline
\end{tabular}

d
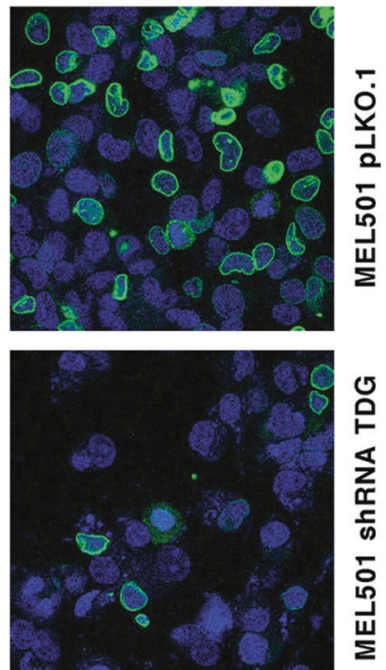

C
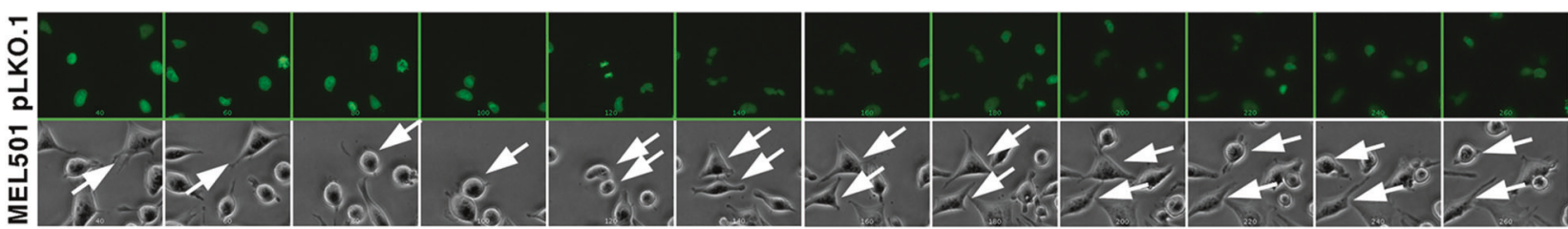

\section{음}

Fig. $2 T D G$ knockdown in melanoma cells induces cell cycle arrest and causes mitotic alterations. a Fluorescence-activated cell sorting (FACS) of propidium iodide-stained parental, TDG knockdown, and control pLKO.1-infected Mel501, Mull, and SK28 cells showing that $T D G$ knockdown induces cell cycle arrest in G2-M phase and S phase, respectively. Cell cycles were analyzed in biological triplicate 4 days after lentivirus infection. b Quantitation of cells in each phase of the cycle is shown. $\mathbf{c}$ Representative images of live cell videomicroscopy of GFP-tagged histone H2B-expressing MEL501 cells infected with

SK28 cells by fluorescence-activated cell sorting (FACS). $T D G$ knockdown perturbed cell cycle dynamics, causing a G2-M arrest in Mel501 and Mull cells and S-phase arrest in SK28 cells (Fig. 2a, b). Importantly, some cells with $T D G$ knockdown escaped the G2-M or S-phase arrest, and

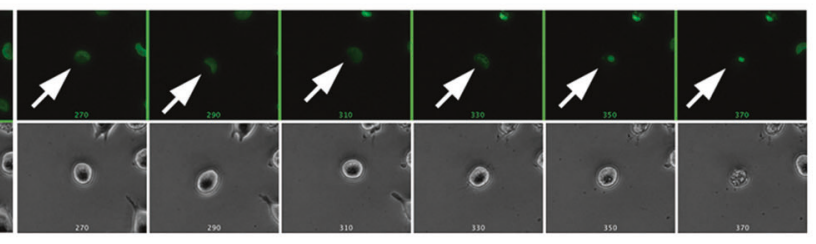

shRNA against TDG and pLKO.1 control lentiviruses and progressing through mitosis. For each time point, bright field (top) and fluorescent (bottom) channels are shown. The time difference between adjacent frames is 300'. Arrows mark cells being tracked; two close arrows signify successful mitosis and two daughter cells. d Immunofluorescence detection of lamin B (green) in parental, TDG knockdown, and control pLKO.1-infected Mel501 cells. Nuclei were counter-stained with DAPI

accumulated $>4 n$ DNA content in agreement with the appearance of multinucleated cells (Fig. 1c).

To better understand the cell cycle arrest associated with $T D G$ knockdown, we used time-lapse videomicroscopy to track the fates of individual Mel501 cells stably expressing 
histone H2B-green fluorescent protein (GFP) after infection with the pLKO or C8 lentivirus. Cells infected with $\mathrm{C} 8$ lentivirus failed to enter mitosis (Fig. 2c). This, along with the cell cycle profile (Fig. 2a, b) and 4,6-diamidino-2-phenylindole (DAPI) staining that confirmed the lack of mitotic cells (Fig. 2d), strongly suggests that the TDG-depleted MEL501 cells are delayed in G2. At later times in the movie, the C8-infected cells exhibited membrane blebbing and pyknotic nuclei, which was followed by cell death (Fig. 2c).

\section{TDG knockdown also induces senescence}

To determine whether the morphological changes (large, flat, dendritic process-bearing, multinucleated cells) observed upon $T D G$ knockdown reflected senescence, we tested the expression of senescence-associated markers. Senescence-associated $\beta$-galactosidase assay (SA- $\beta$-gal) revealed positive staining in C8-infected Mel501 and SK28 cells (Fig. 3a). Consistent with this, western blot analysis showed an increase in the cyclin-dependent kinase inhibitor p16 ${ }^{\mathrm{INK} 4 \mathrm{~A}}$ and decreased lamin B1 (Fig. 3b), Rb, and phospho-Rb (Fig. 3c) in C8-infected Mel501 and SK28 melanoma cells, compared with parental and pLKO.1infected cells. Decreased lamin B1 was confirmed by immunofluorescence (Fig. 2d).

TDG binds to and affects the activity of p300, a transcriptional coactivator that can acetylate each of the core histones as well as non-histone proteins such as $\mathrm{p} 53, \mathrm{Rb}$, and $\mathrm{E} 2 \mathrm{~F}$ and is involved in cellular proliferation, differentiation, and apoptosis [2, 20, 21]. Reduction of p300 levels is known to induce senescence [22]. After TDG knockdown, p300 levels are low to undetectable (Fig. 3c) (As pLKO.1 vectorinfected cells exhibit subtle changes in $\mathrm{Rb}$ and $\mathrm{p} 300$ expression in comparison to parental cells, it is possible that the lentiviral infection per se causes some changes; however, the difference in cellular and molecular phenotypes between pLKO.1- and C8-infected cells is very dramatic.).

To obtain further insight into the mechanism of senescence, we tested the expression of MITF, a master regulator of melanocyte development and a melanoma oncogene [23], whose silencing has been shown to induce senescence [24]. MITF expression was dramatically reduced in C8-infected Mel501 and SK28 melanoma cells (Fig. 3d). MITF is also the main transcriptional regulator of melanoma markers Tyrosinase and Melan-A/MART1 [23, 25]. We detected a dramatic abatement of Tyrosinase and Melan-A/MART1 expression upon $T D G$ knockdown (Fig. 3e-g). Thus reduced MITF expression after $T D G$ knockdown helps explain how these cells undergo senescence. Overexpression of an shRNA-resistant TDG cDNA rescued both MITF expression and morphological changes (Fig. 3h).
We next determined the role of $\mathrm{p} 16^{\mathrm{INK} 4 \mathrm{~A}}, \mathrm{p} 300$, and MITF in TDG knockdown-induced senescence. We found that overexpression of MITF and p300 in C8-infected SK28 cells rescues both the proliferation arrest and the morphological changes associated with $T D G$ knockdown but not the formation of SA- $\beta$-gal-positive cells (Fig. 3i). We also found that co-infection of SK28 cells with shRNA lentiviruses against $\mathrm{p} 16^{\mathrm{INK} 4 \mathrm{~A}}$ and TDG (C8) rescued the proliferation defect. Thus the senescence induced by $T D G$ knockdown was largely (with the exception of SA- $\beta$-galpositivity) suppressed by $16^{\mathrm{INK} 4 \mathrm{~A}}$ silencing and MITF and p300 expression (Fig. 3i).

\section{TDG knockdown affects genes involved in cell cycle and senescence}

The above results show that $T D G$ knockdown causes cell cycle arrest, senescence, and cell death. Given the role of TDG in transcription [2], to gain insight into the changes in gene expression associated with $T D G$ knockdown, we compared the transcriptomes between control and C8-infected SK28 cells 5 days after infection by RNA-seq. Using a $\log 2$ fold change and adjusted $p$ value, $T D G$ knockdown had an important effect on gene expression with more than 1100 significantly downregulated and 1000 upregulated genes (see Supplemental Dataset).

Gene set enrichment analysis (GSEA) revealed marked downregulation of E2F target genes involved in cell cycle progression and DNA replication and repair in C8-infected SK28 cells compared with control pLKO.1-infected cells (enrichment score $(\mathrm{ES})=-0.61$, familywise error rate $p$ value $>0.01$; Fig. $4 a$ ). Similarly, genes associated with G2M checkpoint are also diminished (Fig. 4b); the potent downregulation of these genes reflects the arrested cell cycle of $T D G$ knockdown cells and their entry into senescence [26]. Knockdown of TDG also led to altered metabolic status with reduced expression of genes involved in oxidative phosphorylation (Fig. 4c); the critical role of oxidative phosphorylation in promoting melanoma growth has been recently highlighted by elucidation of the role of SAMMSON [27, 28].

GSEA also revealed upregulation of gene sets designated by the terms "TNF $\alpha$ signaling via NFKB" or "Inflammatory response" (ES, 0.41, $p$ value 0.01 ; Fig. 4d); gene ontology (GO) analysis indicates that many of the genes upregulated in this group encode immune regulators and secreted cytokines and proteases that are known to be part of the senescence-associated secretory phenotype (SASP) [2931]. The heatmaps that compare expression levels for individual genes in each of the four GSEA categories are shown in Suppl. Figure 5. 


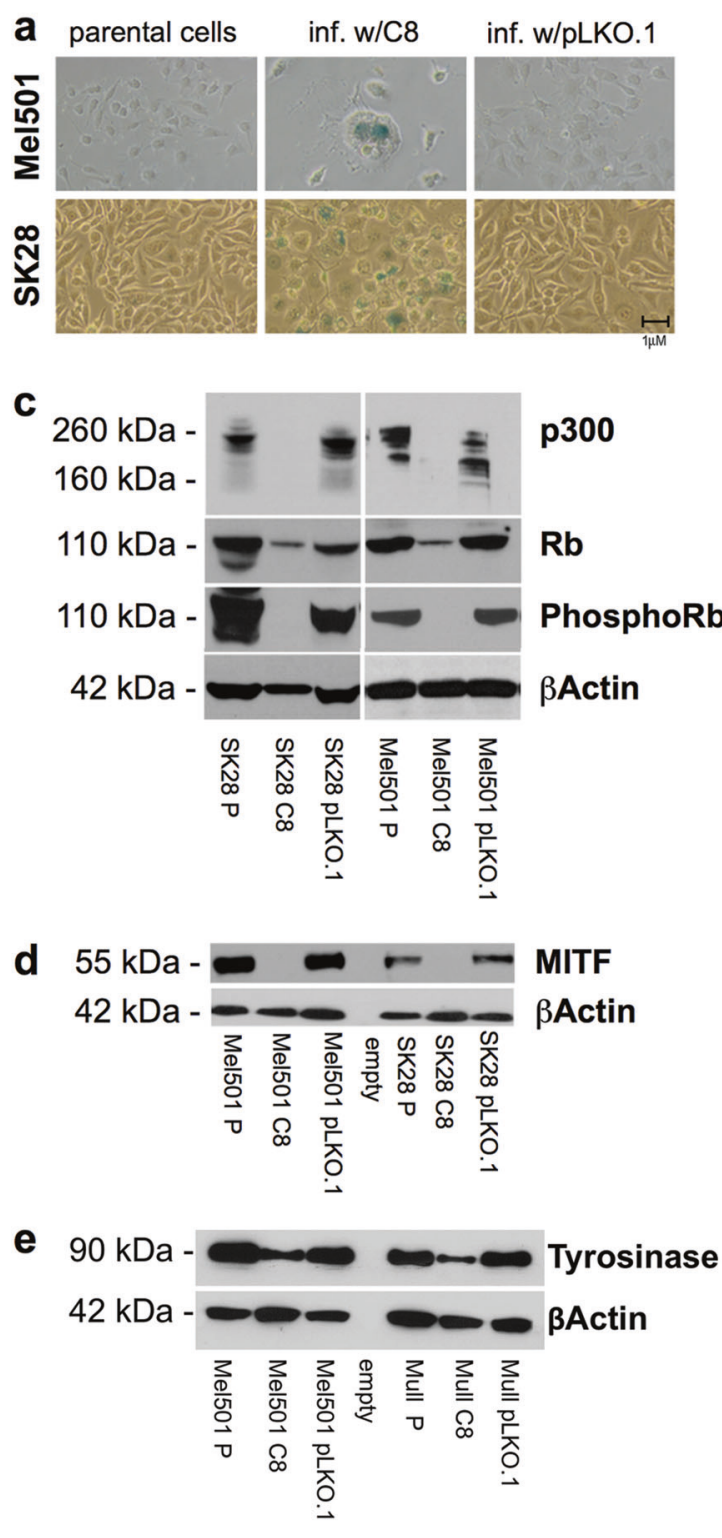

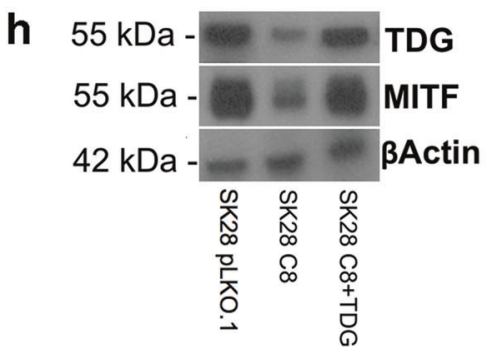

Fig. $3 T D G$ knockdown induces senescence in melanoma. a Senescence-associated $\beta$-galactosidase activity assayed on day 3 postinfection in parental, C8-infected (TDG knockdown), and control pLKO.1-infected SK28 cells. SA- $\beta$-gal-positive cells are stained in blue. b-d Western blot showing the levels of lamin $\mathrm{B}, \mathrm{Rb}$, phospoRb, MITF, p300, and p16 ${ }^{\mathrm{INK} 4 \mathrm{~A}}$ in parental, C8-infected, and pLKO.1infected Mel 501 and SK28 cells 3 days after infection. Lysates are from cells infected at the same time and conditions of those assayed by SA- $\beta$-gal staining. All the experiments were performed in duplicate and $\beta$-actin was used as a loading control. e Western blot detection of
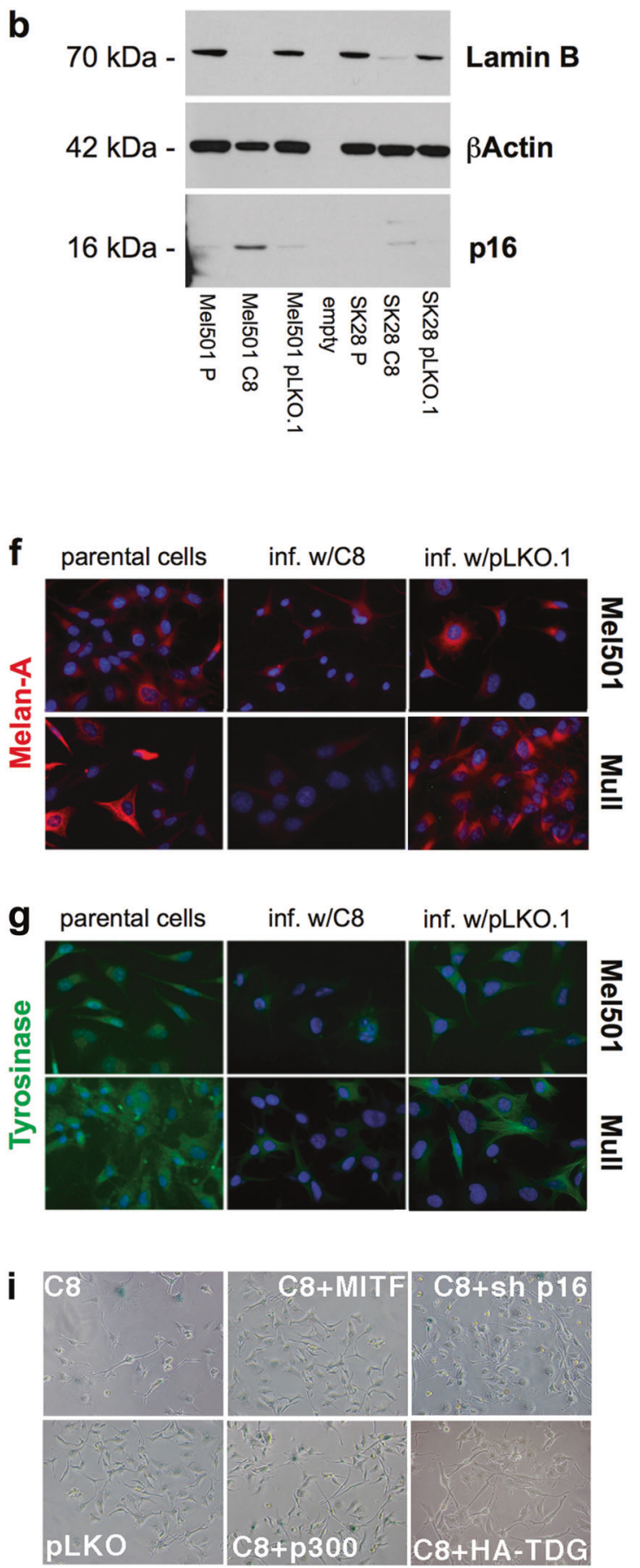

Tyrosinase in parental, TDG knockdown, and control pLKO.1-infected Mel501 and Mull cells. f, g Immunofluorescence detection of MelanA/MART1 (upper panel, red) and Tyrosinase (lower panel, green) in parental, TDG knockdown, and control pLKO.1-infected Mel501 and Mull cell lines. Nuclei were counterstained with DAPI. Expression of shRNA-resistant TDG cDNA in C8-infected MEL501 cells rescues MITF levels (h) and morphological changes (i). Overexpression of MITF and p300 and p16 ${ }^{\text {INK4 }}$ knockdown suppress the morphological changes and proliferation arrest induced by $T D G$ knockdown (i) 


\section{a}

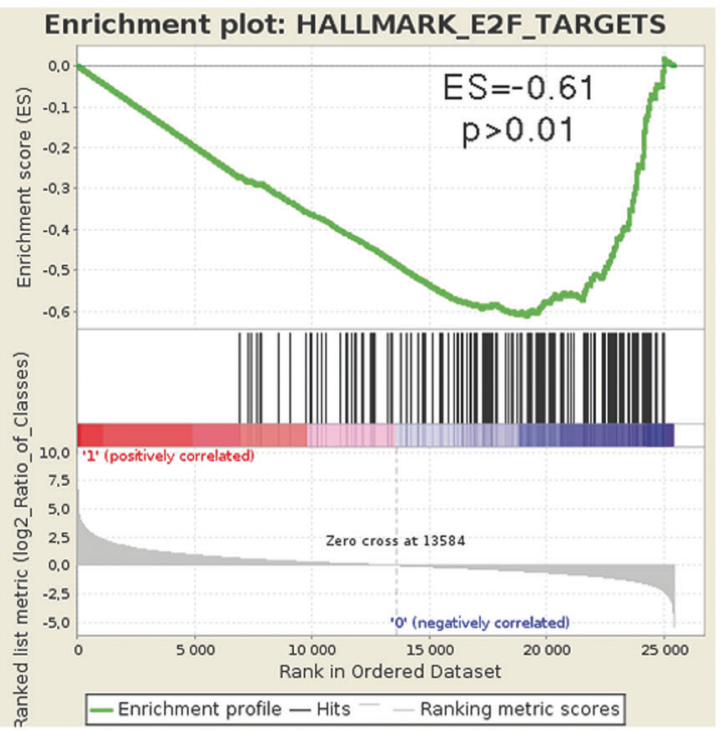

Down-regulated upon TDG knockdown

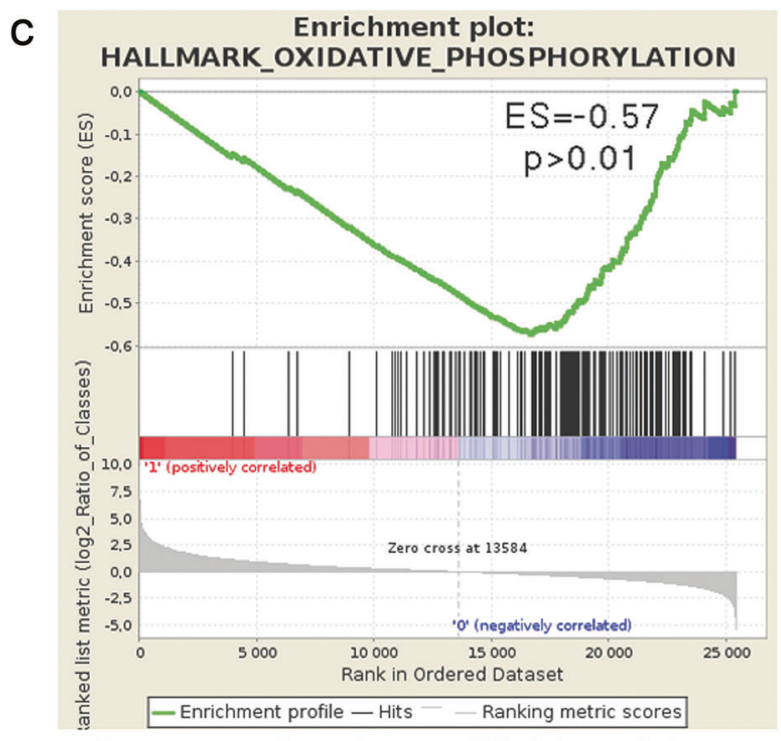

Down-regulated upon TDG knockdown

Fig. $4 T D G$ knockdown affects genes involved in cell cycle regulation, oxidative phosphorylation, and senescence-associated secretory phenotype (SASP), a-d Gene set enrichment analysis (GSEA) of

Thus TDG knockdown SK28 melanoma cells undergo senescence by repression of cell cycle progression genes and expression of SASP genes.

\section{TDG knockdown alters the epigenome by increasing DNA methylation}

Given the role of TDG in DNA demethylation, we began to investigate whether $T D G$ knockdown alters the epigenome of melanoma cell lines. DNA methylation analysis (by digital restriction enzyme analysis of methylation

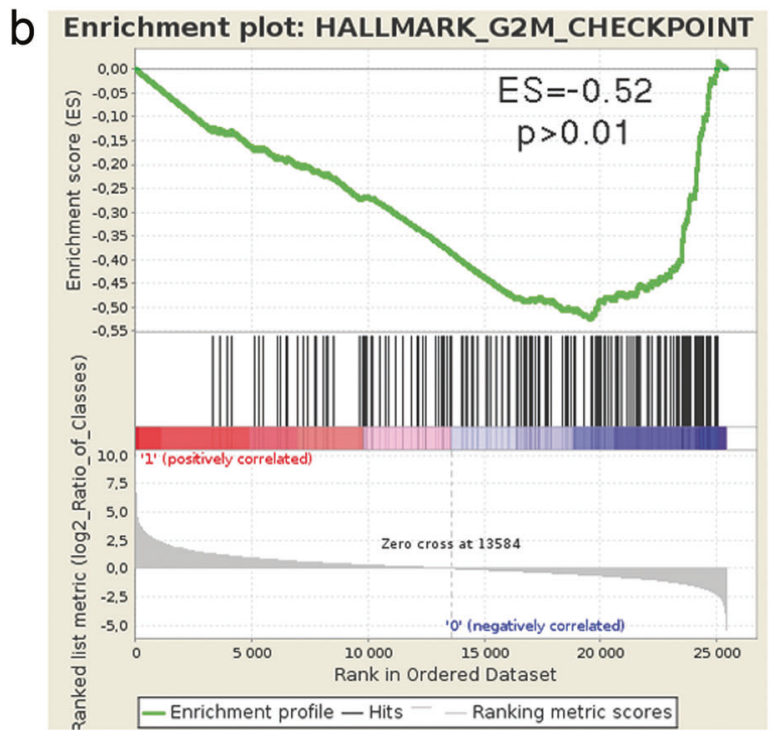

Down-regulated upon TDG knockdown

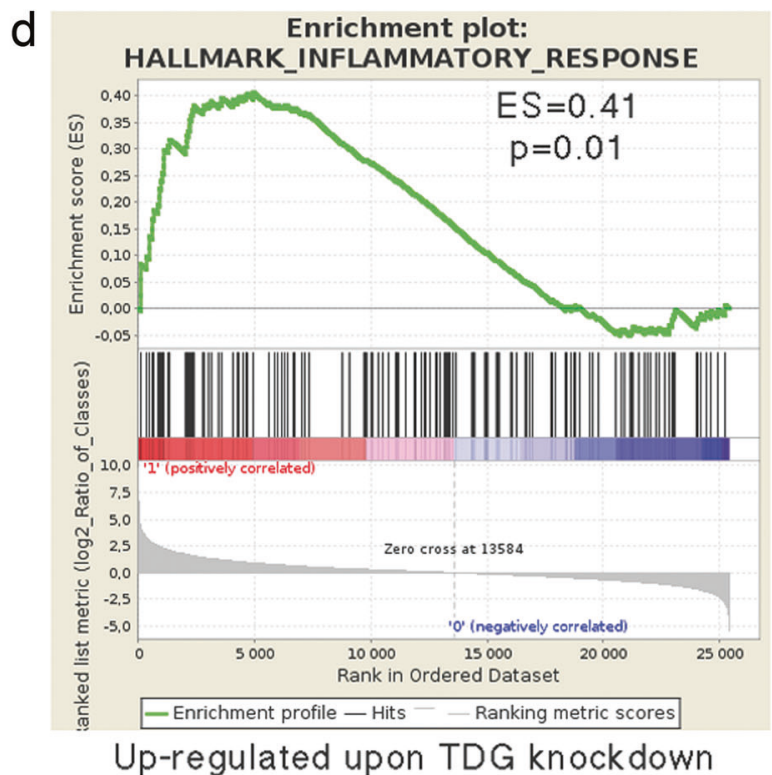

differentially expressed gene sets in C8-infected (TDG knockdown) and control pLKO.1-infected SK28 cells. The most significant categories in the upregulated and downregulated gene sets are shown

(DREAM)) [32] of SK28 and MEL501 melanoma cells infected with TDG shRNA or control lentiviral vector revealed that, upon $T D G$ knockdown, their methylomes were dramatically altered, as evidenced by the $6-7 \%$ increase in hypermethylated $\mathrm{CpG}$ sites and marginal increase in hypomethylated $\mathrm{CpG}$ sites (Fig. 5a, b). A GO analysis of genes mapping next to differentially methylated (hypo/hypermethylated) $\mathrm{CpG}$ sites in SK28 and MEL501 cells showed the involvement of pathways of transcriptional regulation, development, proliferation, and differentiation (Fig. 5c, d). Thus, in keeping with its role in 


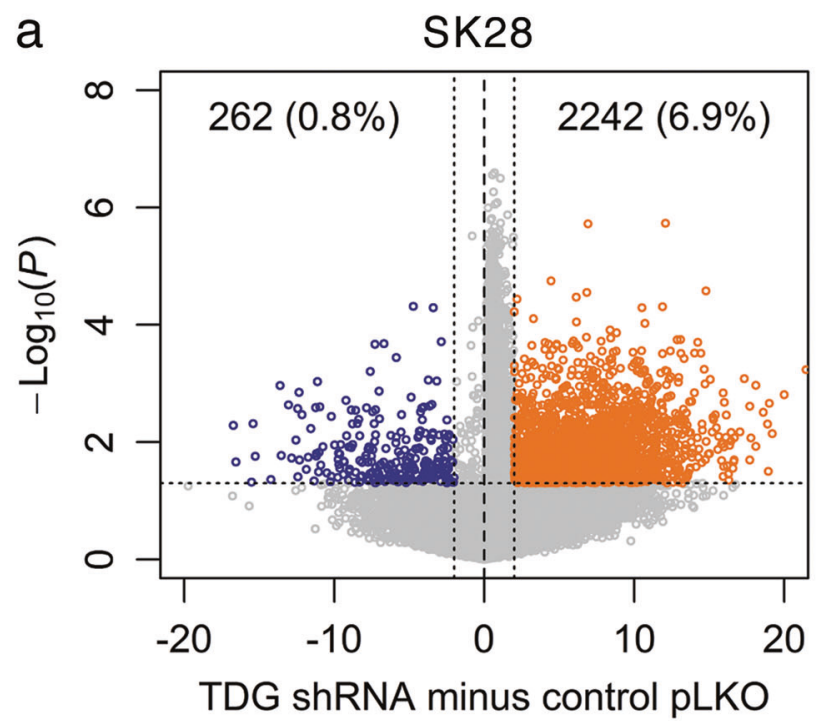

C
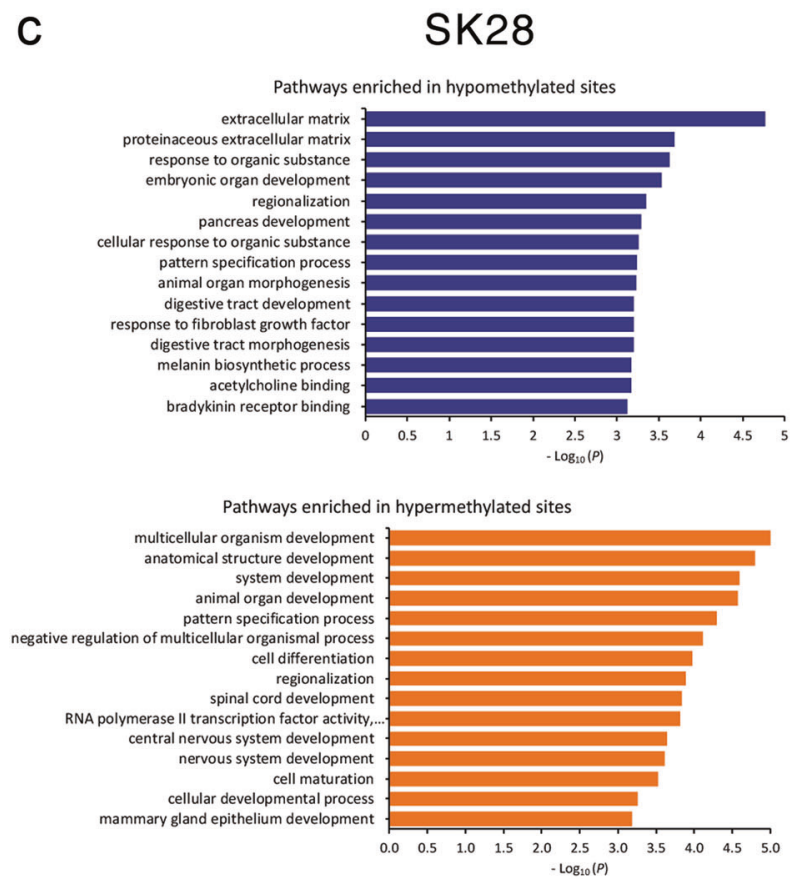

Fig. $5 T D G$ knockdown affects the epigenome. Volcano plots show CpG sites differentially methylated by TDG knockdown in SK28 (a) and MEL501 (b) melanoma cells; blue and orange dots show hypomethylated and hypermethylated sites, respectively. The percentage of

DNA demethylation, $T D G$ knockdown alters the epigenome by increasing DNA methylation.

\section{TDG knockdown reduces tumor growth in vivo}

To investigate whether $T D G$ knockdown affected tumor formation in vivo, parental, C8-, and pLKO.1-infected SK28 cells were evaluated for tumor formation in NGS
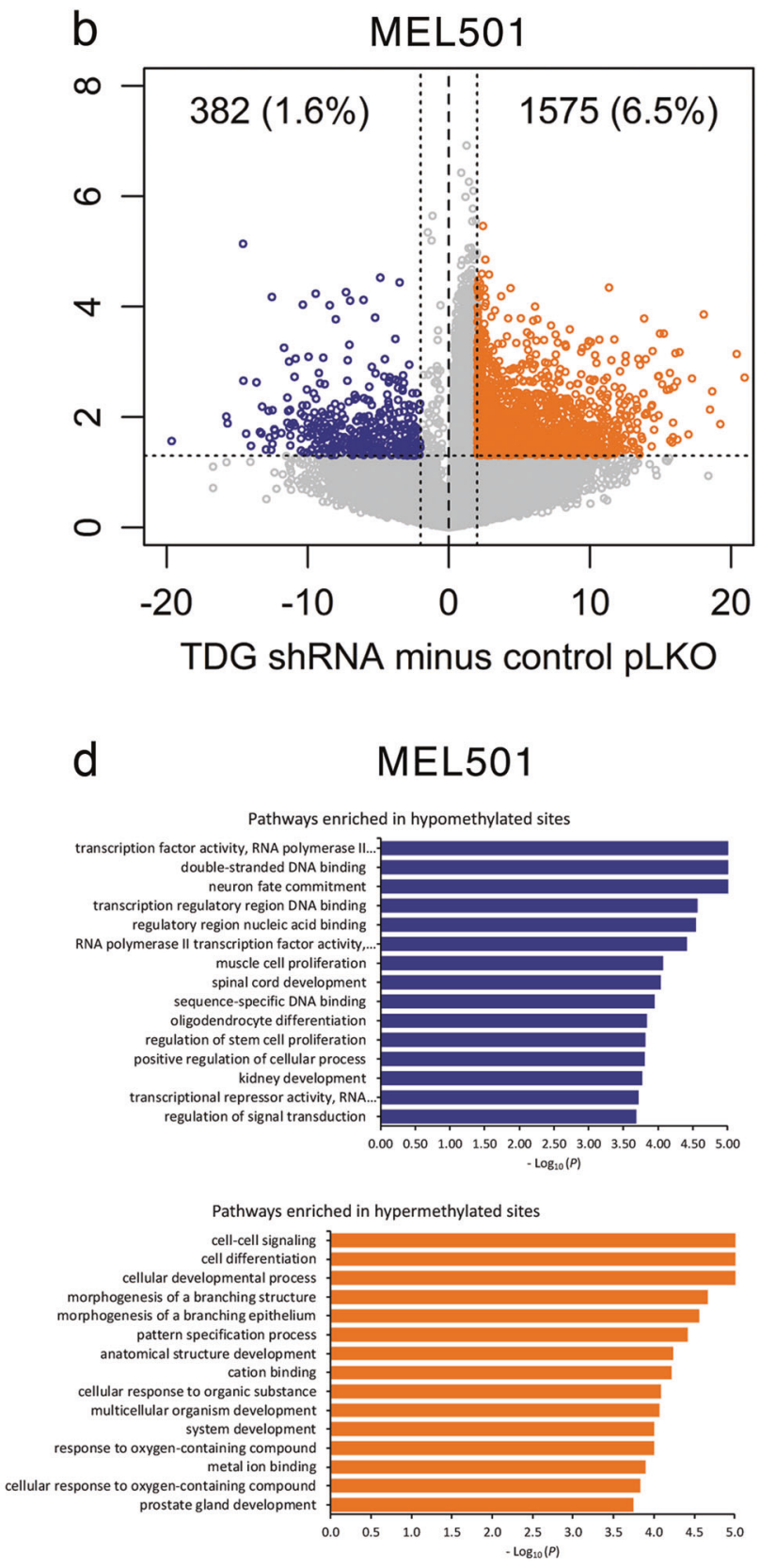

CpG sites undergoing changes in methylation upon TDG knockdown is indicated. Pathway analysis of genes mapping next to hypomethylated and hypermethylated CpG sites in SK28 (c) and MEL501 (d) cells. $x$ axis: $-\log _{10}(p)$

mice by injecting them subcutaneously into the flanks of six mice for each study arm. Tumors from $T D G$ knockdown SK28 xenografts grew significantly smaller than tumors from control SK28 xenografts (Fig. 6a), and at the end of the study, the average tumor weight of $T D G$ knockdown xenografts was approximately half of control pLKO.1 or parental xenografts $(p<0.00006$ and $p<0.0009$, respectively) (Fig. 6b). Similar results were obtained with the Mull 

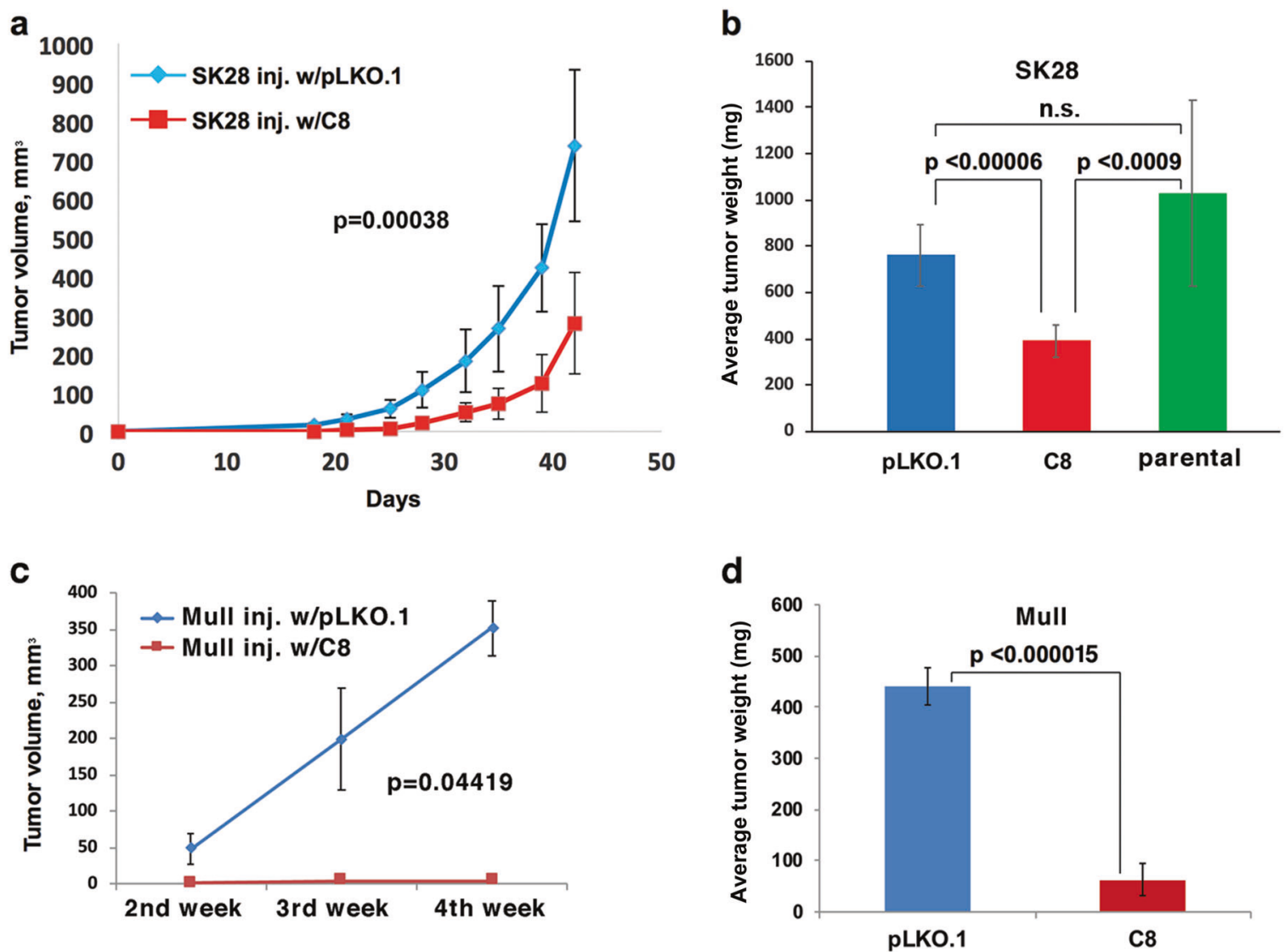

Fig. $6 T D G$ knockdown inhibits the tumorigenic potential of SK28 and Mull melanoma cells. a Tumor growth curves of xenografts of control pLKO.1 vector-infected or C8-infected (TDG knockdown) SK28 cells injected subcutaneously into the flank of NSG mice. Data are presented as average \pm standard deviation. b Average weight, at the end of the experiment, of tumors from xenografts of parental, control pLKO.1 vector-, and C8-infected SK28 cells. $p$ Value was calculated

cell line ( $p<0.000015$; Fig. 6c, d). Thus TDG knockdown reduces the ability of melanoma cells to form tumors in xenotransplant assay.

\section{Lack of toxicity of TDG inactivation in non- transformed cells/tissues}

These results suggest that $T D G$ inactivation may represent a viable anticancer strategy but raise the possibility of toxic effects on non-transformed cells. To test the effect of TDG inactivation in non-transformed cells in vitro, we knocked down TDG in HEMn-LP (Fig. 7a), a non-transformed melanocytic cell line, and compared their proliferation to that of $T D G$ knockdown SK28 cells, over an incubation time of $190 \mathrm{~h}$ by xCELLigence real-time cell analyzer. Starting at $55 \mathrm{~h}$, in comparison to matched pLKO-infected cells, $T D G$ knockdown significantly decreased the proliferation of SK28 melanoma cells but had a smaller effect on normal melanocytic cells, starting at $\sim 80 \mathrm{~h}$, perhaps due to their lower growth rate (Fig. 7b-d; Suppl. Figure 6).

by Fisher's exact test; n.s. not significant. c Tumor growth curves of xenografts of control pLKO.1 vector-infected or C8-infected (TDG knockdown) Mull cells injected subcutaneously into the flank of NSG mice. d Average weight, at the end of the experiment, of tumors from xenografts of parental, control pLKO.1 vector-, and C8-infected Mull cells

To investigate the effects of $T D G$ inactivation in normal adult tissues and rule out potential toxic effects in vivo, we generated conditional $T d g$ knockout mice, bypassing embryonic lethality associated with germline $T d g$ inactivation $[2,4]$. We used Cre- $E R^{T 2}$ transgenic mice in which tamoxifen-inducible Cre recombinase is driven by the ubiquitous human $U B C$ promoter [33]; thus inactivation of the $T d g^{\text {flox }}$ allele would be expected in most tissues of the mice. A total of 45 mice were divided into two genotype groups: experimental Cre-ER $T d g^{\text {flox/- }}$ and control Cre- $E R^{T 2}$ $T d g^{\text {flox/+}}$. After tamoxifen administration by oral gavage, the deletion of $T d g^{\text {flox }}$ allele was confirmed by quantitative PCR (qPCR) on DNA extracted from blood (Fig. 7e). Cre-ER ${ }^{T 2}$ $T d g^{\text {flox } /-}$ and Cre- $E R^{T 2} T d g^{\text {flox } /+}$ mice were aged and monitored for neoplastic lesions or general morbidity over a 3month period after tamoxifen administration. Early deaths occurred within the first 10 days (Fig. 7f) and could be attributed to non-specific consequence of the tamoxifen gavage; in fact, oral gavage is known to be associated with a $15 \%$ mortality, due to esophageal perforation or gastro- 

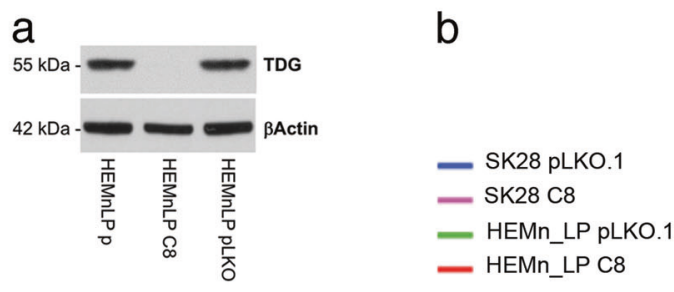

C
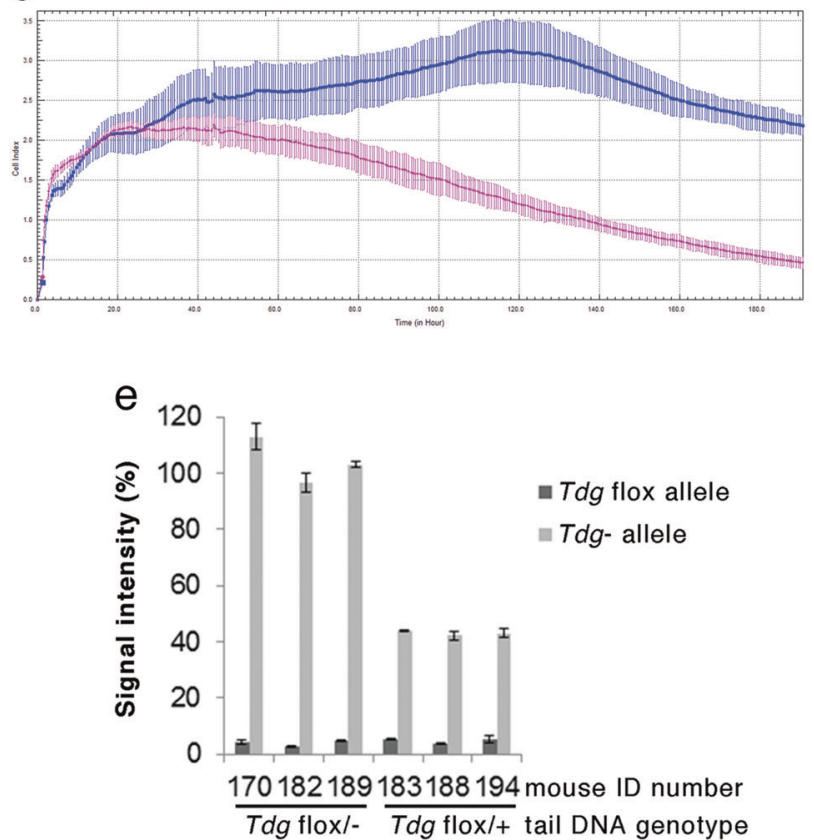

Fig. 7 Lack of toxicity of TDG inactivation in non-transformed cells and adult mice. a Western blot showing effective $T D G$ knockdown in C8-infected (TDG knockdown) but not in control pLKO.1-infected HEMn-LP normal, non-transformed melanocytes. b Cell proliferation analysis over an incubation time of $190 \mathrm{~h}$ by xCELLigence real-time cell analyzer in C8- and pLKO.1-infected HEMn-LP melanocytes and SK28 melanoma cells. All the experiments were performed in duplicate and are presented as average \pm standard deviation. The same proliferation data are shown for SK28 melanoma cells only (c) and

esophageal reflux and consequent pneumonia [34, 35]. Upon further aging, no significant differences in survival were observed between the two genotype groups (Fig. 7f). At 3 months after tamoxifen treatment, mice were sacrificed and inspected for the presence of tissue abnormalities or gross phenotypes. No significant macroscopic differences were found between experimental Cre- $E R^{T 2} T d g^{\text {flox/- }}$ mice and control Cre- $E R^{T 2} T d g^{\text {flox/+ }}$ mice. However, in 2/4 Cre$E R^{T 2} T d g^{\text {flox/- }}$ mice for which histopathological analysis was conducted, a histiocytic proliferation was detected in the liver and spleen; histiocytic proliferation was not found in $0 / 4 \mathrm{Cre}-E R^{T 2} T d g^{\text {flox/+ }}$ mice that underwent histopathological analysis (Suppl. Figure 7). The significance of these

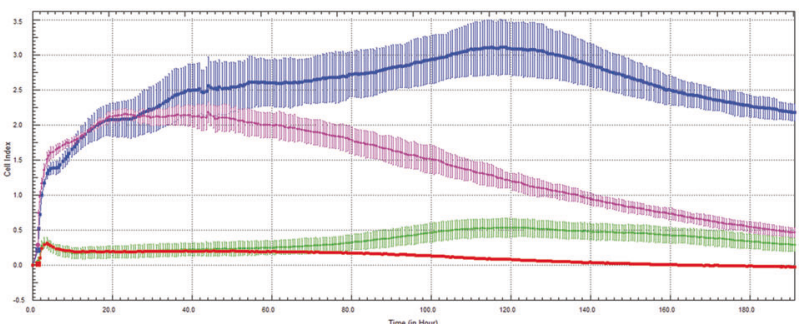

d
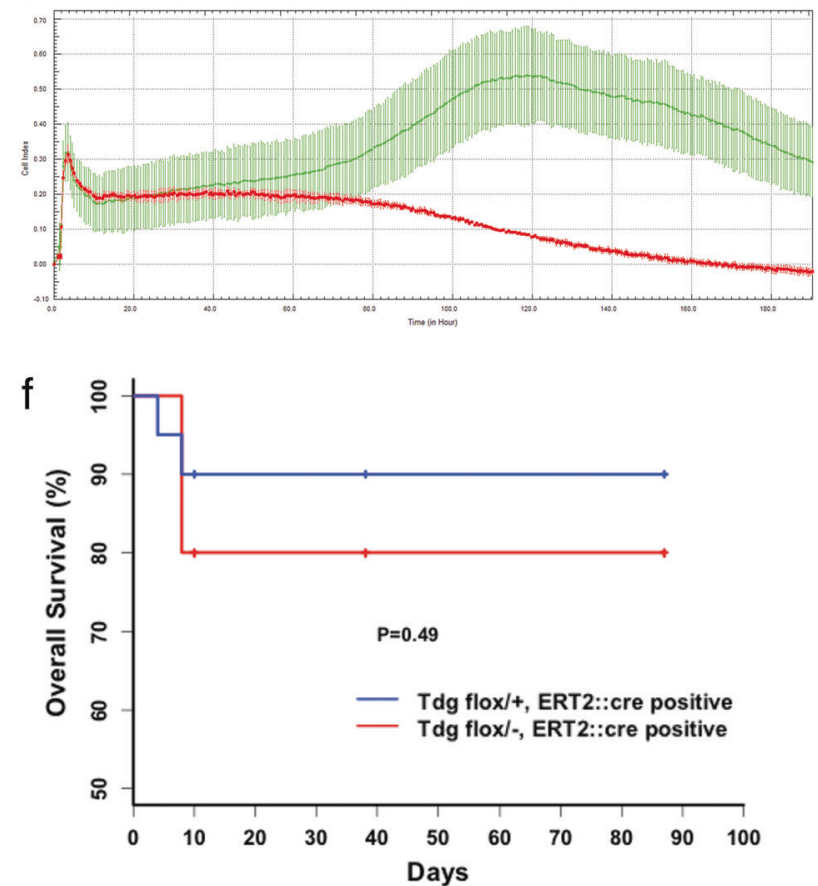

HEMn-LP melanocytes only (d). e Quantitation by qPCR of Cremediated recombination of the $T d g^{\text {flox }}$ allele and conversion into $T d g-$ allele in the blood from Cre-ER $T d g^{\text {flox/- }}$ and Cre-ER $T d g^{\text {flox/+ }}$ mice. The data are expressed as percentage of signal intensity in comparison to that of the Anf gene. f Kaplan-Meier analysis of experimental $T d g^{\text {flox/-}}-\mathrm{Cre}-E R^{T 2}$ mice $(n=30)$ and control $T d g^{\text {flox } /}$ ${ }^{+}{ }_{-}$Cre- $E R^{T 2}$ mice $(n=15)$; time zero corresponds to tamoxifen administration. $p$ Value is calculated by Fisher's exact test

histopathological findings and their relationship to TDG inactivation are unclear, because histiocytosis has been reported to be associated with oral gavage [35].

Thus in vitro and in vivo results indicate that, unlike tumor cells, TDG is dispensable in normal cells and tissues, which rules out significant toxicity in normal cells and tissues due to $T D G$ inactivation.

\section{Identification of candidate TDG inhibitors}

The antiproliferative effects of $T D G$ knockdown in cancer cells raise the possibility that small molecule inhibitors that catalytically inactivate TDG may be useful for melanoma 
treatment. To identify inhibitors of TDG glycosylase activity, we employed an in vitro DNA repair molecular beacon assay in which a hairpin-shaped G:U-mismatched oligonucleotide is incubated with highly active preparations of recombinant TDG and recombinant AP endonuclease (APE1), the latter acting as a downstream coupling enzyme. In the folded hairpin substrate, the fluorescence of 5'-conjugated 6-FAM is quenched by a dabsyl "black hole" at the 3' end [18]. Upon removal of the mismatched U by TDG, and incision of the resulting abasic/AP site by APE1, a short oligonucleotide containing 6-FAM is released away from the quencher. The resulting fluorescence is monitored on a real-time qPCR machine over a $2 \mathrm{~h}$ incubation at $37^{\circ} \mathrm{C}$, providing a sensitive and quantitative measurement of repair activity (Suppl. Figure 7a). Because the assay is bienzymatic, we first established the dose dependence of both APE1 and TDG in 384-well format (Suppl. Figure 7b-c).

After optimizing the assay for 384-well format ( $Z^{\prime}$ score $0.6)$ [36], we screened the ICCB bioactive library ( $\sim 500$ compounds) and the Johns Hopkins Clinical Compound library ( 1500 drugs), identifying 18 and 14 candidate inhibitors, respectively (Suppl. Tables 1 and 2; Fig. 8a, b). Subsequently, the TDG assay was successfully miniaturized in the 1536-well format ( $Z$ ' score 0.6) [36] and a new screen was conducted against the Sigma Aldrich LOPAC ${ }^{1280}$ compound library in a dose-response fashion that allowed us to compare the $\mathrm{IC}_{50}$ of compounds, identifying 16 positive hits, which upon elimination of promiscuous hits and DNA binders were reduced to 9 compounds (Suppl. Table 3). One of these compounds is aurothioglucose, a glucose derivative used for rheumatoid arthritis that had also been identified in the 384-well format screening. Some of these compounds, including closantel, juglone, and cefixime, were confirmed as TDG inhibitors in a standard, radioactive DNA glycosylase assay (Fig. 8c, d).

\section{Candidate TDG inhibitors reduce cell viability and clonogenic capacity in melanoma cells}

We next performed MTS [3-(4,5-dimethylthiazol-2-yl)-5(3-carboxymethoxyphenyl)-2-(4- sulfophenyl)-2H-tetrazolium] and clonogenic assays in juglone- and closanteltreated SK28 cells. After $24 \mathrm{~h}$ exposure to each drug, we detected a dose-dependent reduction of cell viability by MTS assays, with $\mathrm{IC}_{50}$ of approximately $10 \mu \mathrm{M}$ for juglone and closantel (Fig. 8e, f). In agreement with the MTS results, we observed a dose-dependent reduction of colony formation in clonogenic assays, with $\mathrm{IC}_{50}$ of approximately 10 and $40 \mu \mathrm{M}$ for juglone and closantel, respectively (Fig. $8 \mathrm{~g}-\mathrm{j})$. To determine whether these two drugs target TDG at concentrations comparable to their $\mathrm{IC}_{50}$, nuclei of jugloneand closantel-treated SK28cells at $10 \mu \mathrm{M}$ were stained for $5 \mathrm{caC}$ : the results showed increased $5 \mathrm{caC}$ staining compared to dimethyl sulfoxide (DMSO)-treated cells, confirming TDG inhibition (Fig. 8k, 1). In addition, juglone treatment recapitulated the $\mathrm{G} 2-\mathrm{M}$ cell cycle arrest of $T D G$ knockdown in MEL501 and increased the percentage of $S$ phase and $>4 n$ cells in SK28 (Fig. 8m, n). Treatment of normal melanocytic cell line HEMn-LP with juglone and closantel elicited a reduction in viability (Suppl. Fig. 9). Together, these results demonstrate that TDG inhibition can arrest tumor cell growth and eventually induce cell death.

\section{Discussion}

Our studies show that TDG is required for melanoma cell proliferation, survival, and tumor formation. TDG knockdown caused a robust cell cycle arrest, cell death, and a senescent phenotype. Gene expression profiling of $T D G$ knockdown cells showed upregulation of known melanoma SASP genes, hallmark of senescence, and downregulation of cell cycle factors, such as E2F target genes and DNA replication genes, which may explain the cell cycle arrest.

$T D G$ knockdown seems to affect melanoma cells irrespective of TP53/BRAF/NRAS mutational status; in fact MEL501, Mull, and SK28 harbor a BRAF-V600E mutation, whereas Gerlach cells are NRAS mutant, and MNT-1 are wild type for both $B R A F$ and NRAS. However, the mutational background of a given cell line may determine different responses to $T D G$ knockdown; for instance, the Sphase arrest of SK28 cells, as opposed to the G2-M arrest of MEL501 and Mull cells, may be related to the fact that SK28 cells contain a TP53 mutation (L145R).

In addition to its role in DNA repair and active DNA demethylation, TDG has also been implicated in transcriptional regulation as co-activator of several transcription factors, including histone acetyltransferases p300 and CBP [2]. We recently reported that TDG promotes histone acetylation by p300 and affects p300 selectivity on specific histone H3 lysines (K18 and K23) in melanoma [20]. Interestingly, p300 and CBP acetylate MITF and act as MITF co-activators. Importantly, depletion of p300 and MITF in melanoma cells has been show to induce cell cycle arrest and a senescent phenotype [37-39]. A complex transcriptional network might also regulate the levels of these factors. In fact, MITF binds to the $T D G$ promoter [29]. Thus it is possible that $T D G$ knockdown causes senescence in melanoma cells by decreasing the levels and activity of p300 and MITF, which in turn may further deplete TDG by reducing its transcription. Overexpression of p300 and MITF rescues the proliferation arrest and morphological changes induced by TDG knockdown but not the SA- $\beta$-galpositivity, thus confirming the decreased levels of p300 and MITF as a possible mechanism of TDG knockdowninduced senescence. Multinucleation, a feature of 

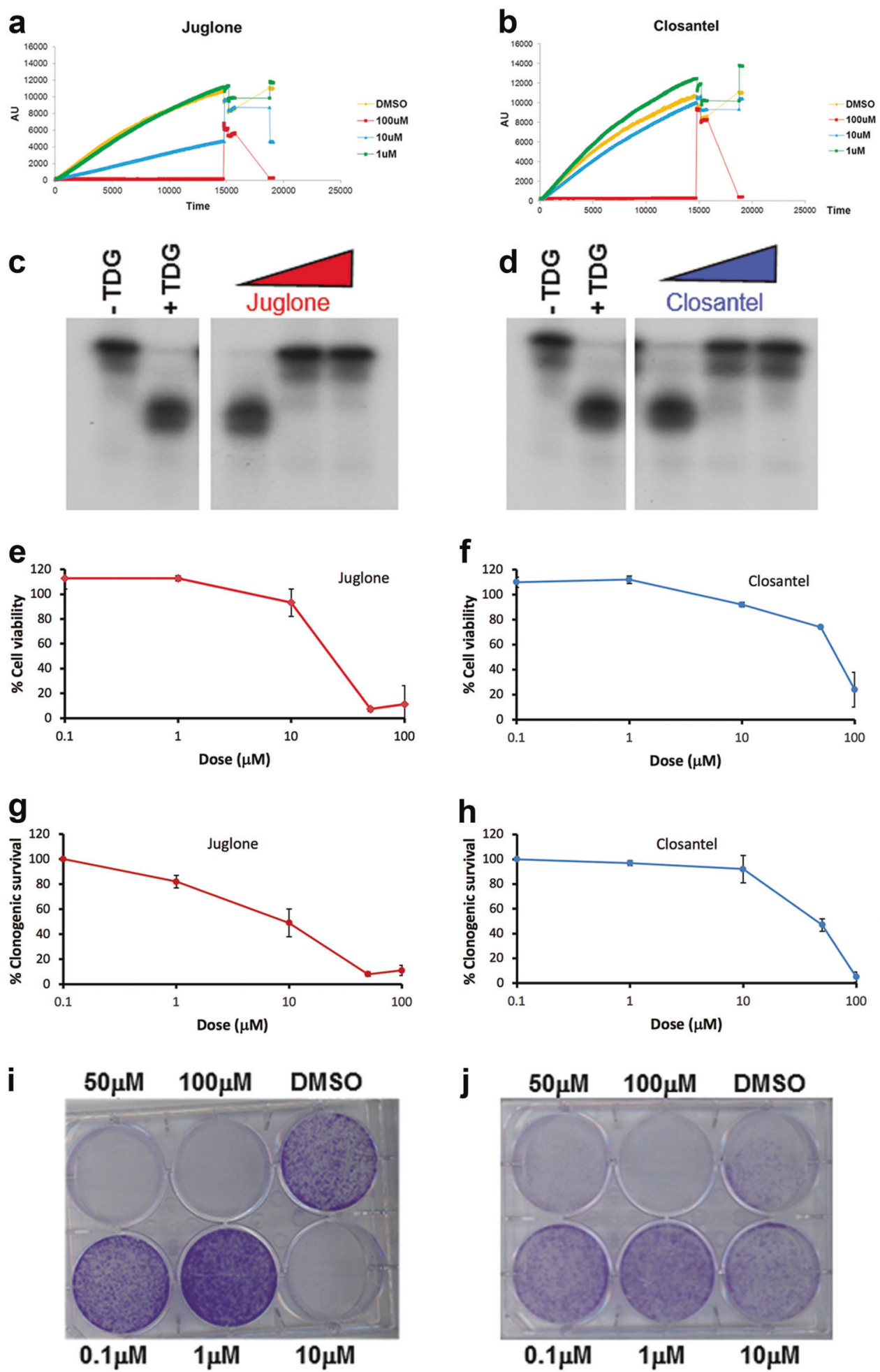

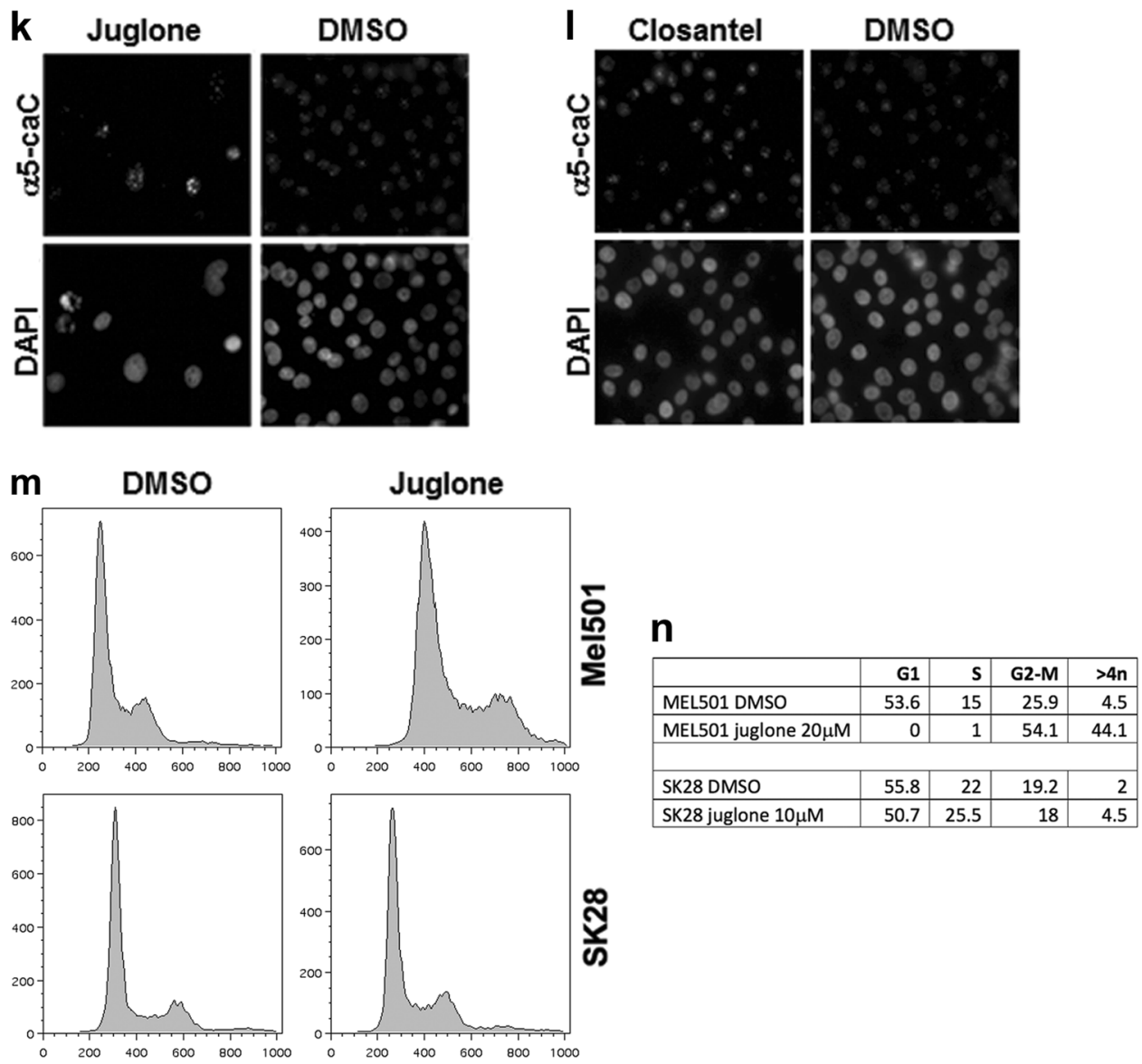

Fig. 8 TDG inhibitors decrease clonogenic capacity and cell viability in melanoma cells. a, b Molecular beacon DNA repair assay showing dose-dependent inhibition of TDG glycosylase activity by juglone and closantel, respectively; fluorescence is in arbitrary units (AU); time is in 0.5-s intervals. c, $\mathbf{d}$ Conventional TDG glycosylase assays, in which G:T mismatch-bearing double-stranded oligonucleotide substrates and ${ }^{32} \mathrm{P}$-labeled at the $3^{\prime}$ end on the mismatched T-containing strand were treated with purified recombinant TDG protein at $37^{\circ} \mathrm{C}$; the reactions were then treated with $100 \mathrm{mM} \mathrm{NaOH}$ at $90^{\circ} \mathrm{C}$ for $30^{\prime}$ in order to cleave the sugar-phosphate backbone at the AP site and the resulting reaction product was separated from the longer substrate by PAGE. Juglone and closantel were tested at concentrations of $100 \mathrm{nM}, 10 \mu \mathrm{M}$, and $1 \mathrm{mM}$. A negative control is included. e, f Cell viability of SK28

melanoma cells treated with increasing doses of juglone and closantel. g, h Clonogenic capacity of SK28 melanoma cells treated with different doses of juglone and closantel or DMSO as a control; i, j corresponding stained plates. All the experiments were performed in duplicate or triplicate and data, normalized to DMSO, are presented as average \pm standard deviation. $\mathbf{k}$, $\mathbf{l}$ Detection by immunofluorescence of $5 \mathrm{caC}$ in juglone- and closantel-treated SK28 cells; DMSO was used as a negative control; nuclei were counter-stained with DAPI. m, nFluorescence-activated cell sorting (FACS) of propidium iodidestained Mel501 and SK28 cells, showing that juglone induces cell cycle arrest in $\mathrm{G} 2-\mathrm{M}$ phase and increased $\mathrm{S}$ phase $/>4 n$ cells, respectively

senescent cells expressing high levels of p16 $6^{\mathrm{INK} 4 \mathrm{~A}}$ (ref. [40]), was also seen as an adaptation to p300 silencing [41]. It is possible that the very low levels of $\mathrm{Rb}$ and lack of $\mathrm{pRb}$ in $T D G$ knockdown cells may further enhance multinucleation. The rescue of the proliferation arrest by $\mathrm{p} 16^{\mathrm{INK} 4 \mathrm{~A}}$ knockdown indicates that the $\mathrm{p} 16^{\mathrm{INK} 4 \mathrm{~A}}-\mathrm{Rb}$ pathway is also involved in TDG knockdown-induced senescence, an issue that merits additional studies in future and that may clarify the relationship among proliferation arrest and multinucleation. The persistence of SA- $\beta$-gal-positivity after suppression of TDG knockdown-induced senescence by $\mathrm{p} 16^{\mathrm{INK} 4 \mathrm{~A}}$ silencing and MITF and $\mathrm{p} 300$ expression is interesting. It should be noted that SA- $\beta$-gal can be positive in biological conditions other than senescence (reviewed in ref. [42]); alternatively, as hypothesized for phosphoinositide-3 kinase/phosphatase and tensin homolog signaling [42], fine-tuning of TDG expression levels may be necessary to maintain cell proliferation and counteract senescence; therefore, in rescue experiments by transient transfection, cells that express just the appropriate amount of TDG for the desired rescue phenotype may be few.

The appearance of dendritic processes in melanoma cells upon $T D G$ knockdown is a distinctive morphological feature that renders them similar to dendritic melanocytes, 
which are found in $\mathrm{Braf}^{\mathrm{V} 600 \mathrm{E}}$-induced nevi and stain positive for SA- $\beta-$ Gal activity [43]. Also, it has been noted that senescent cells may adopt a dendritic shape [44]. Thus dendrites may be a morphological feature of $T D G$ knockdown-induced senescence of melanoma cells.

Time-lapse microscopy of Mel501 cells showed that $T D G$ knockdown also caused cell death following what is presumably a cell cycle arrest in G2 (as determined by FACS). The precise involvement of TDG in preventing these alterations not only requires additional studies but may also be related to the reduced levels of p300, as depletion of $\mathrm{p} 300, \mathrm{CBP}$, or P/CAF leads to mitotic catastrophe in human cell lines [41].

We found that $T D G$ knockdown alters the epigenome by increasing hypermethylated $\mathrm{CpG}$ sites by $6-7 \%$, in keeping with its role in DNA demethylation. It was thought originally that, when cells were treated with the DNA demethylating agents azacitidine or decitabine, genome-wide demethylation would cause significant toxicity. However, it was later found that only select regions of the genome were demethylated by these drugs $[45,46]$. Here the same thing, but in a specular way, occurs after TDG inactivation: a small but significant fraction of the genome undergoes hypermethylation, which suggests that TDG inhibitors will not cause non-specific and generalized toxicity through massive genome hypermethylation.

Importantly, $T D G$ knockdown strongly suppresses the tumor-forming capabilities of melanoma lines in xenograft assays, suggesting that one or more of TDG activities are critical for tumor induction, maintenance, and/or progression and therefore may potentially represent a novel vulnerability of melanoma.

The miniaturized screening assay that we devised, amenable to high-throughput applications, led to the identification of first-generation TDG inhibitors that reduced viability and clonogenic capacity of melanoma lines. Since these inhibitors have $\mathrm{IC}_{50}$ in the low micromolar range and have hit in other screening campaigns, we cannot rule out off-target effects. However, they must inhibit TDG in cellular context, because they increase the normally undetectable levels of $5 \mathrm{caC}$. First-generation TDG inhibitors also reduced viability of normal melanocytes, which may also be a consequence of off-target effects.

While some of these inhibitors are Food and Drug Administration approved, such as aurothioglucose, others are not suitable for human use (juglone, closantel). Our findings nonetheless highlight the utility of our screen in identifying chemicals that can inhibit TDG activity. It is not clear whether the drugs identified could be repurposed or modified by medicinal chemistry, as opposed to looking for more potent and specific hits by screening larger compound libraries. Identification of more potent and specific inhibitors of TDG is probably a better strategy to overcome the cytotoxicity on normal melanocytes (Suppl. Fig. 9). However, the fact that untransformed melanocytes are minimally affected by $T D G$ knockdown and only show reduced proliferation starting at $80 \mathrm{~h}$ (whereas melanoma cells have marked reduction in cell index starting at $55 \mathrm{~h}$, Fig. $7 \mathrm{~b}-\mathrm{d}$ ), and that conditional knockout of $T D G$ in adult mice is well tolerated (Fig. 7f), rules out significant toxicity in normal cells/tissues due to specific TDG inactivation and indicates that it should be possible to achieve an effective therapeutic window. In fact, evidence so far accumulated suggests that the normal role of TDG may be limited largely to development and that therapeutic targeting may spare adult somatic cells.

Future experiments will address in more detail the specific requirement of TDG for cancer cells, which, based on particular mutations and epigenetic alterations of the individual tumor, should both enable the identification of patients more likely to benefit from a therapy with TDG inhibitors and begin to establish rational basis for combinatorial treatments of TDG inhibitors with existing antimelanoma drugs.

\section{Materials and methods}

\section{Cell culture}

SK28, 888-Mel (from ATCC), Mull, Rosi (from Benoit van den Eynde), Mel501 (from Colin Goding), and MNT-1 (from Graça Raposo) were validated by comparative genomic hybridization and cultured in RPMI-1640 supplemented with $10 \%$ fetal bovine serum, $1 \%$ penicillin/streptomycin, and $1 \%$ L-glutamine. A non-transformed epidermal melanocytic line HEMn-LP (from Raza Zaidi) was cultured in Medium 254 (Invitrogen) supplemented with Human Melanocyte Growth Supplement (Invitrogen).

\section{Western blot analysis}

Western blotting was conducted as previously described [20]. Membranes were incubated with antibodies anti-TDG, anti-lamin B1 (both Abcam), anti-p16 ${ }^{\mathrm{INK} 4 \mathrm{~A}}$ (Santa Cruz Biotechnology), anti-p300 (Calbiochem), anti-Rb, antiphosphoRb (both Cell Signaling), anti-MITF (Interchim), and anti- $\beta$-actin (Sigma).

\section{TDG knockdown by lentiviral infection}

Two different $T D G$ shRNA lentiviral constructs, named C8 (Thermo Scientific Open Bio-Systems) and sh4575 (SigmaAldrich), and the empty pLKO.1 lentiviral vector were used in this study. $T D G$ knockdown was performed as previously described [2]. Control pLKO.1 and TDG shRNA lentivirus- 
infected melanoma cell lines were selected in puromycin $(0.5 \mu \mathrm{g} / \mathrm{mL})$ for 3-5 days. For the experiments of overexpression of TDG, MITF, and $\mathrm{p} 300$, infections were conducted $24 \mathrm{~h}$ after transfection of these clones (by Lipofectamine 2000, Thermo Fisher); 4-5 days later, the transfected/infected cells were fixed for SA- $\beta$-gal activity (see below). Transfection/infection experiments were repeated four times.

\section{Cell cycle analysis}

Cell cycle analysis was conducted as previously described [47] by collecting both attached cells and cells floating in the medium. Samples were analyzed in biological triplicate with a FACScan (Becton Dickinson) using the FLOW-JO software (Tree Star, Ashland, OR). Cell cycle quantitation was conducted with the Dean/Jett/Fox method, using FLOW-JO.

\section{Cell viability assay}

SK28 cells, seeded in 96-well plates (at 2000-5000 cells/ well), were treated with vehicle or drugs at the indicated concentrations for 24,48 , or $72 \mathrm{~h}$. Viability was measured with MTS, using the Cell Titer 96 Assay (Promega). Absorbance was measured in a Synergy HT plate reader (Biotek). All experiments were conducted in triplicate.

\section{Clonogenic assay}

Clonogenic capacity was determined as previously described [47]. Briefly, $24 \mathrm{~h}$ after seeding, DMSO (vehicle control) or drugs at the indicated concentrations were added for $24 \mathrm{~h}$. Drugs were removed and replaced with drug-free medium. After 10-14 days, the cells were stained with Clonogenic Dye (4\% Crystal Violet powder in $20 \%$ EtOH) for 30'. Individual colonies were counted. Each clonogenic assay was tested in triplicate or quadruplicate.

\section{Cell proliferation}

Cell proliferation was measured with the xCELLigence Real-Time Cell Analysis, using modified 16-well E-plates (ACEA Biosciences, Inc., San Diego, CA). SK28 and HEMn-LP cells were seeded at $4 \times 10^{3}$ and $1.5 \times 10^{4}$ cells/ well, respectively, and proliferation was monitored in realtime over $81 \mathrm{~h}$. Each condition was tested in duplicate.

\section{$\beta$-Galactosidase activity}

SA- $\beta$-gal activity was detected at $\mathrm{pH} 6.0$ [48]. Mel501 and SK28 cells, plated into a 6-well plate onto cover slips at 1$1.5 \times 10^{5}$ cells/well, were stained with $40 \mathrm{mM} \mathrm{Na} 2 \mathrm{HPO}_{4}$,
pH 6.0, $150 \mathrm{mM} \mathrm{NaCl}, 2 \mathrm{mM} \mathrm{MgCl} \mathrm{MM} \mathrm{K}_{3}, 5 \mathrm{Fe}(\mathrm{CN})_{6}, 5$ $\mathrm{mM} \mathrm{K}{ }_{4} \mathrm{Fe}(\mathrm{CN})_{6}$, and $1 \mathrm{mg} / \mathrm{mL}$ 5-bromo-4-chloro-3-indolyl $\beta$-D-galactopyranoside (X-gal) at $37^{\circ} \mathrm{C}$ for $5-7 \mathrm{~h}$ in the dark into a non- $\mathrm{CO}_{2}$ incubator. Cells were fixed for 5 ' at room temperature in $2 \%$ formaldehyde $/ 0.2 \%$ glutaraldehyde in phosphate-buffered saline (PBS), rinsed in PBS and eventually in $\mathrm{ddH}_{2} \mathrm{O}$, and then photographed with a phasecontrast microscope.

\section{Immunofluorescence}

Cells were seeded onto acid-washed coverslips and cultured for at least $24 \mathrm{~h}$ before fixation and staining. Cells were fixed (4\% paraformaldehyde in PBS for 10'), permeabilized for 1-2' at room temperature with $0.2 \%$ Triton X-100 in KB buffer $(20 \mathrm{mM}$ Tris- $\mathrm{HCl}, \mathrm{pH} 7.5,150 \mathrm{mM} \mathrm{NaCl}$, and $1 \%$ bovine serum albumin (BSA)), washed in KB, and blocked with 3\% BSA in PBS for $1 \mathrm{~h}$. Primary antibodies anti-5caC (Active Motif), anti-tyrosinase, and anti-Melan-A (both from Santa Cruz Biotechnology) were incubated overnight at $4{ }^{\circ} \mathrm{C}$. After washing twice in $\mathrm{KB}$, samples were incubated with Alexa Fluor-conjugated anti-rabbit (Molecular Probes) for 30'. Nuclei were counterstained with DAPI. The nuclear envelope was detected by immunofluorescence staining of lamin B using a mouse monoclonal antibody (Abcam) and following protocol provided by the vendor. Images were taken using a Leica Microsystems TCS-SP8A confocal microscope controlled by the LAS software. Exposure times were optimized for control samples and identical exposure times were used for experimental samples.

\section{Time-lapse videomicroscopy}

Forty-eight hours after lentiviral infection, Mel501 cells stably expressing GFP:histone H2B were seeded into 6-well plates in complete RPMI medium+puromycin, supplemented with HEPES $(25 \mathrm{mM})$, layered with mineral oil (Sigma), and placed into housing chamber at $37^{\circ} \mathrm{C}$. Images were acquired every $15^{\prime}$ for $72 \mathrm{~h}$ on Nikon TE300 inverted epi-fluorescent microscope (Nikon Instruments) with Retiga EXi CCD camera (QImaging). Images were compiled into video using the MetaMorph software (Molecular Devices). Cell fates were analyzed frame by frame.

\section{Xenografts}

SK28 cells were resuspended within Matrigel and injected in SCID/NSG female mice $\left(5 \times 10^{6}\right.$ cells/flank). Mice were observed daily and tumor volumes were measured twice a week with digital caliper. Tumor volumes were calculated as: (length $\times$ width $\left.^{2}\right) / 2$ (ref. [49]). When xenografts in vehicle-treated mice reached $\sim 1.5 \mathrm{~cm}$ diameter, mice were sacrificed. We referred to similar published studies in which 
six animals per arm are used. Mice were housed in the Fox Chase Cancer Center Laboratory Animal Facility, a fully accredited facility, and all experiments were approved by the Fox Chase Cancer Center Institutional Animal Care and Use Committee.

\section{Conditional inactivation of $T d g$ in adult mice}

For conditional inactivation of $T d g$ in adult mice, we crossed Cre-ER ${ }^{T 2}$ transgenic mice [33] (gift of Eric Brown) with $T d g^{\text {flox/flox }}$ conditional knockout mice [50]. All the strains used have a nearly pure C57BL/6 genetic background (at least 10 backcrosses in this background). To inactivate the $T d g^{\text {flox }}$ allele, we treated Cre-ER $T R^{T 2} T g^{-/ \text {flox }}$ mice and control Cre- $E R^{T 2} T d g^{\text {flox/+ }}$ mice with tamoxifen (Sigma T-5648), $20 \mathrm{mg} / \mathrm{mL}$ in corn oil (Sigma C-8267), by oral gavage, three times per mouse every other day, using a $1 \mathrm{~mL}$ syringe and a $20-\mathrm{G}$ sterile 1.5 " curved feeding needle with $2.25 \mathrm{~mm}$ ball (Braintree Scientific N-PK 01022). Total administration of tamoxifen was $6 \mathrm{mg}$ per mouse. Tamoxifen treatments were conducted on randomized animals (genotype unknown to the experimenter).

After 3 weeks from the last gavage, $T d g$ genotyping was performed on DNA extracted from blood collected from retro-orbital bleeding by the QIAamp DNA Blood Mini Kit (Qiagen). Experimental Cre- $E R^{T 2} T d g^{\text {flox/- }}$ and control Cre$E R^{T 2} T d g^{\text {flox/+ }}$ mice with an extensive $T d g^{\text {flox }}$ allele deletion, as determined by qPCR, were included in this study, monitored weekly, and sacrificed at the first development of signs of distress or at a maximum of 90 days. A KaplanMeier analysis was performed and statistical significance was measured using log-rank test.

\section{RNA sequencing}

RNA (biological triplicates) was prepared with the RNeasy Mini Kit (Qiagen), and quality control was performed on a Bioanalyzer. Messenger-RNA-seq was performed essentially as described [51]. Sequence reads were mapped to reference genome mm9/NCBI37 using Tophat v2.0.10 [52] and the bowtie 2 v2.1.0 aligner [53]. Only uniquely aligned reads were retained for further analyses. Data normalization and quantification of gene expression was performed using the DESeq2 Bioconductor package. Significantly deregulated genes were selected using a $\log 2$ fold change $>1$ and $<1$ and adjusted $p$ value cutoff of 0.05 . GO analyses were performed using DAVID functional annotation clustering tool (https://david.ncifcrf.gov/summary.jsp). For GSEA, we used the mean of the $\log 2$ fold changes of the biological replicates as metric for the $\mathrm{H}$ Hallmark gene sets of the BROAD javaGSEA tool with 1000 permutations and the canonical pathway subcollection of the C2-curated BROAD molecular signature gene set collection. Comparisons of interest were performed [54] as implemented in the DESeq2 Bioconductor library (v1.0.18). Resulting $p$ values were adjusted for multiple testing by the Benjamini and Hochberg method [55]. Heatmaps were made using the $\log 2$ of RPKM values with R package "pheatmap" v1.0.10 using options scale $=$ 'none' and cluster_rows $=$ TRUE. For heatmaps of deregulated genes, only the 300 most upregulated or downregulated genes were represented.

\section{Analysis of DNA methylation by DREAM}

DREAM was performed to determine the methylation profile of MEL501 and SK28 melanoma cell lines (biological duplicates). Briefly, genomic DNA spiked with methylation standards was sequentially digested by SmaI and XmaI, which both recognize the sequence CCCGGG. SmaI is methylation sensitive, whereas XmaI is methylation insensitive. Distinct signatures, 5'-GGG at unmethylated sites or 5'-CCGGG at methylated sites, were created by enzyme digestion. 3' recesses were filled in, and Illumina adaptors were ligated to the ends of restriction fragments. Barcoded library pools were sequenced using Illumina HiSeq2500 instrument. Illumina fastq files were aligned to the human genome (hg19) using Bowtie2 [53]. Uniquely mapped reads were sorted into bam files using SAMtools [56, 57]. We used a Python script to map aligned sequencing reads to target CCCGGG sites in the human genome and enumerate signatures corresponding to methylated (starting with CCGGG) and unmethylated (starting with GGG) CpG for each target site. We calculated methylation levels at each $\mathrm{SmaI} / \mathrm{XmaI}$ site based on the percentage of methylated signatures. Background-corrected GO analyses were performed using ConsensusPathDB (http://cpdb.molgen.mpg.de).

\section{Screening assay}

TDG/APE1 activity was measured using a G:U-mismatched DNA repair molecular beacon in which the substrate adopts a hairpin structure, with quenching upon folding and fluorescence release upon base removal/cleavage at the lesion site [18]. The substrate (Biosearch Technologies, Novato, CA) was: 5'dT(FAM)-CCACT-d-UridineGTGAATTGACAGCCCATGTGCATCAATTCACGAG-

TGG-T(Dabsyl)3', where FAM and Dabsyl are conjugated to the thymine C5 carbon, to avoid degradation of the fluorophores by the exonuclease of APE1 [58]. The substrate was allowed to fold by heating at $94{ }^{\circ} \mathrm{C}$ for 3 ' and cooling to $4{ }^{\circ} \mathrm{C}$ at $0.1^{\circ} \mathrm{C} / \mathrm{s}$ at $100 \mu \mathrm{M}$ in $4 \times$ BER buffer ( $1 \times$ : Hepes-KOH 25 mM, KCl $150 \mathrm{mM}$, Glycerol 1\%, DTT 0.5 $\mathrm{mM}$ ). Recombinant APE1 (NEB) and recombinant TDG [2] were diluted to 0.5 and $0.25 \mu \mathrm{M}$ respectively in $40 \mathrm{mM}$ Hepes-KOH, $100 \mathrm{mM} \mathrm{NaCl}$, and $10 \%$ glycerol. Substrate and enzymes were mixed and dispensed in 384-well plates 
(10 $\mu \mathrm{L} /$ well) to final concentrations of $280 \mathrm{nM}$ (substrate), $30 \mathrm{nM}$ (TDG), and $60 \mathrm{nM}$ (APE1) in $1 \times$ BER buffer supplemented with $\mathrm{MgCl}_{2}(1.2 \mathrm{mM})$, DTT $(10 \mathrm{mM})$, and BSA $(0.5 \mathrm{mg} / \mathrm{mL}, \mathrm{NEB})$. The ICCB Known Bioactives Library (Enzo Life Sciences) and the Johns Hopkins Clinical Compound Library [59] were screened. Compounds varied in concentration from $0.1 \mathrm{mM}$ to $10 \mathrm{mM}$. Compounds dissolved in DMSO were added to wells of 384-well plates by pin-tool transfer on a CyBi-Well Vario (Analytik Jena AG, Jena, Germany) equipped with a $25 \mathrm{~nL}$ pin-tool ( $\mathrm{V}$ and $\mathrm{P}$ Scientific). The reaction was initiated by bringing the plate to $37^{\circ} \mathrm{C}$ in a real-time PCR machine (Applied Biosystems $7900 \mathrm{HT}$ ). FAM fluorescence was recorded for $2 \mathrm{~h}$ at $0.5-\mathrm{s}$ intervals.

\section{Assay miniaturization in 1536-well format}

To utilize fully automated robotic platforms for doseresponse screening, the previous assay was miniaturized into 1536-well format by not only miniaturizing the reaction volume $(4 \mu \mathrm{L})$ but also by optimizing enzyme concentrations. Briefly, $3 \mu \mathrm{L}$ of reagents (buffer as negative control and $100 \mathrm{nM}$ of TDG and $3 \mathrm{nM}$ of APE1) were dispensed by Flying Reagent Dispenser ${ }^{\mathrm{TM}}$ (Beckman Coulter Inc.) into $1536-w e l l$ plates. Compounds were delivered as $23 \mathrm{~nL}$ in DMSO via pin-tool transfer; vehicle-only control consisted of $23 \mathrm{~nL}$ DMSO. The plate was incubated for 15' at room temperature, and then $1 \mu \mathrm{L}$ of folded hairpin substrate (100 $\mathrm{nM}$ ) was added to start the reaction. The plate was immediately transferred into ViewLux reader to measure fluorescence signal at 0 and $3 \mathrm{~h}$. $\mathrm{IC}_{50}$ values were calculated from dose-response curve fits using the fluorescence intensity change, relating it to uninhibited and no-enzyme controls, respectively. The assay was used to screen the LOPAC $^{1280}$ library of bioactive compounds (SigmaAldrich).

\section{DNA glycosylase assay}

DNA glycosylase assays were conducted as previously described $[2,60]$ on a G:U mismatched substrate obtained by annealing the oligonucleotides CAATCCTAGCTGACACGATGTGGCCAATGGCATGACT and GAGTCAT GCCATTGGCCACATUGTGTCAGCTAGGATT [61], in which the latter was radiolabeled at the $5^{\prime}$ end with $\mathrm{T} 4$ polynucleotide kinase (New England Biolabs) and $\gamma_{-}{ }^{32} \mathrm{P}-$ ATP (NEN Dupont). The reactions, containing vehicle or candidate inhibitors at increasing concentrations, were incubated at $37^{\circ} \mathrm{C}$ for $30^{\prime}$ and then treated with $\mathrm{NaOH}$ at $90^{\circ} \mathrm{C}$ for $30^{\prime}$ to cleave the abasic site. Substrate and product bands were separated by $8.3 \mathrm{M}$ urea/ $25 \%$ polyacrylamide gel electrophoresis and exposed to autoradiography.

\section{Bioinformatics analysis}

Oncomine 4.5 database (http://www.oncomine.org) was used to investigate the expression of $T D G$ in normal skin, nevi, and cutaneous melanoma samples in the Talantov melanoma dataset. The Human Protein Atlas pathology database (http://www.proteinatlas.org) was used to assess TDG protein expression in human melanoma and to investigate the correlation between $T D G$ mRNA expression level and patient survival by Kaplan-Meier analysis.

\section{Data availability}

The datasets generated during and/or analysed during the current study have been submitted to the GEO repository at accession numbers GSE123681 and GSE123928.

Acknowledgements We thank Dr. P. Abbosh and Dr. I. Astsaturov for critical reading of the manuscript; Dr. R. Zaidi for comments and advice; L. Cathay for secretarial assistance; and John and Robin Spurlino and the Edwards Family for their generous support of this research. We would like to thank Alice M. Hungerford for her philanthropic funding through the David A. Hungerford Endowed Fund in Basic Chromosome Research, honoring her late husband's legacy as a renowned scientist and the co-discoverer of the Philadelphia Chromosome. We thank the following core services at Fox Chase Cancer Center: Genomics, Cell Culture, Cell Sorting, Biological Imaging, High-Throughput Screening, Biostatistics and Bioinformatics, and Laboratory Animal Facilities. This study was supported by NIH grants CA78412 (to A. Bellacosa), CA191956 (to A. Bellacosa and T. Yen), and CA06927; the intramural research program of the National Center for Advancing Translational Sciences (NCATS), National Institutes of Health (NIH), PA Department of Health C.U.R.E. and an appropriation from the Commonwealth of Pennsylvania to the Fox Chase Cancer Center. PM was supported in part by INCa Project PLBIO11027. RT was supported in part by a William J. Avery Endowed Postdoctoral Fellowship. RWS was supported by grants from the National Institutes of Health (CA148629 and ES025138) and is an Abraham A. Mitchell Distinguished Investigator. LL was supported by a grant from Ligue Nationale Contre le Cancer, INCa, ITMO cancer, and is under the program "Investissements d'Avenir" launched by the French Government and implemented by ANR Labex CelTisPhyBio (ANR-11-LBX-0038 and ANR-10-IDEX-0001-02 PSL). Work in the laboratory of ID was supported by grants from the INCa, the Ligue National contre le cancer, and the Labex INRT (ANR-10-IDEX-000102). RNA-seq was performed at the IGBMC high-throughput sequencing facility, a member of "France Génomique" consortium (ANR10-INBS-09-08). LL and ID are "equipes labélisées of the Ligue National Contre le cancer." AB would like to dedicate this article to the memory of his mother Maria, who showed that strength and tenderness, elegance and simplicity, resilience and joyfulness can coexist, and who will be missed tremendously.

\section{Compliance with ethical standards}

Conflict of interest The authors declare that they have no conflict of interest.

Publisher's note: Springer Nature remains neutral with regard to jurisdictional claims in published maps and institutional affiliations. 
Open Access This article is licensed under a Creative Commons Attribution 4.0 International License, which permits use, sharing, adaptation, distribution and reproduction in any medium or format, as long as you give appropriate credit to the original author(s) and the source, provide a link to the Creative Commons license, and indicate if changes were made. The images or other third party material in this article are included in the article's Creative Commons license, unless indicated otherwise in a credit line to the material. If material is not included in the article's Creative Commons license and your intended use is not permitted by statutory regulation or exceeds the permitted use, you will need to obtain permission directly from the copyright holder. To view a copy of this license, visit http://creativecommons. org/licenses/by/4.0/.

\section{References}

1. Gray-Schopfer V, Wellbrock C, Marais R. Melanoma biology and new targeted therapy. Nature. 2007;445:851-7.

2. Cortellino S, Xu J, Sannai M, Moore R, Caretti E, Cigliano A, et al. Thymine DNA glycosylase is essential for active DNA demethylation by linked deamination-base excision repair. Cell. 2011;146:67-79.

3. Dalton SR, Bellacosa A. DNA demethylation by TDG. Epigenomics. 2012;4:459-67.

4. Cortazar D, Kunz C, Selfridge J, Lettieri T, Saito Y, Macdougall $\mathrm{E}$, et al. Embryonic lethal phenotype reveals a function of TDG in maintaining epigenetic stability. Nature. 2011;470:419-23.

5. Bellacosa A, Drohat AC. Role of base excision repair in maintaining the genetic and epigenetic integrity of $\mathrm{CpG}$ sites. DNA Repair 2015;32:33-42.

6. Cortazar D, Kunz C, Saito Y, Steinacher R, Schar P. The enigmatic thymine DNA glycosylase. DNA Repair (Amst). 2007;6:489-504.

7. He YF, Li BZ, Li Z, Liu P, Wang Y, Tang Q, et al. Tet-mediated formation of 5-carboxylcytosine and its excision by TDG in mammalian DNA. Science. 2011;333:1303-7.

8. Maiti A, Drohat AC. Thymine DNA glycosylase can rapidly excise 5-formylcytosine and 5-carboxylcytosine: potential implications for active demethylation of $\mathrm{CpG}$ sites. J Biol Chem. 2011;286:35334-8.

9. Hayward NK, Wilmott JS, Waddell N, Johansson PA, Field MA, Nones K, et al. Whole-genome landscapes of major melanoma subtypes. Nature. 2017;545:175-80.

10. Song F, Amos CI, Lee JE, Lian CG, Fang S, Liu H, et al. Identification of a melanoma susceptibility locus and somatic mutation in TET2. Carcinogenesis. 2014;35:2097-101.

11. Berger MF, Hodis E, Heffernan TP, Deribe YL, Lawrence MS, Protopopov A, et al. Melanoma genome sequencing reveals frequent PREX2 mutations. Nature. 2012;485:502-6.

12. Hodis E, Watson IR, Kryukov GV, Arold ST, Imielinski M, Theurillat JP, et al. A landscape of driver mutations in melanoma. Cell. 2012;150:251-63.

13. Krauthammer M, Kong Y. Exome sequencing identifies recurrent mutations in NF1 and RASopathy genes in sun-exposed melanomas. Nat Genet. 2015;47:996-1002.

14. Krauthammer M, Kong Y, Ha BH, Evans P, Bacchiocchi A, McCusker JP, et al. Exome sequencing identifies recurrent somatic RAC1 mutations in melanoma. Nat Genet. 2012;44:1006-14.

15. Gao J, Aksoy BA, Dogrusoz U, Dresdner G, Gross B, Sumer SO, et al. Integrative analysis of complex cancer genomics and clinical profiles using the cBioPortal. Sci Signal. 2013;6:pl1-19.

16. Lian CG, Xu Y, Ceol C, Wu F, Larson A, Dresser K, et al. Loss of 5-hydroxymethylcytosine is an epigenetic hallmark of melanoma. Cell. 2012;150:1135-46.
17. Gambichler T, Sand M, Skrygan M. Loss of 5hydroxymethylcytosine and ten-eleven translocation 2 protein expression in malignant melanoma. Melanoma Res. 2013;23:21820.

18. Svilar D, Vens C, Sobol RW. Quantitative, real-time analysis of base excision repair activity in cell lysates utilizing lesion-specific molecular beacons. J Vis Exp. 2012:e4168.

19. Rambow F, Job B, Petit V, Gesbert F, Delmas V, Seberg H, et al. New functional signatures for understanding melanoma biology from tumor cell lineage-specific analysis. Cell Rep. 2015;13:84053.

20. Henry RA, Mancuso P, Kuo YM, Tricarico R, Tini M, Cole PA, et al. Interaction with the DNA repair protein thymine DNA glycosylase regulates histone acetylation by $\mathrm{p} 300$. Biochemistry. 2016;55:6766-75.

21. Shiama N. The p300/CBP family: integrating signals with transcription factors and chromatin. Trends Cell Biol. 1997;7:230-6.

22. Prieur A, Besnard E, Babled A, Lemaitre JM. p53 and p16 (INK4A) independent induction of senescence by chromatindependent alteration of S-phase progression. Nat Commun. 2011;2:473.

23. Levy C, Khaled M, Fisher DE. MITF: master regulator of melanocyte development and melanoma oncogene. Trends Mol Med. 2006;12:406-14.

24. Giuliano S, Ohanna M, Ballotti R, Bertolotto C. Advances in melanoma senescence and potential clinical application. Pigment Cell Melanoma Res. 2011;24:295-308.

25. Du J, Miller AJ, Widlund HR, Horstmann MA, Ramaswamy S, Fisher DE. MLANA/MART1 and SILV/PMEL17/GP100 are transcriptionally regulated by MITF in melanocytes and melanoma. Am J Pathol. 2003;163:333-43.

26. Narita M, Nunez S, Heard E, Lin AW, Hearn SA, Spector DL, et al. $\mathrm{Rb}$-mediated heterochromatin formation and silencing of E2F target genes during cellular senescence. Cell. 2003;113:70316.

27. Goding CR. Targeting the lncRNA SAMMSON reveals metabolic vulnerability in melanoma. Nature. 2016;29:619-21.

28. Leucci E, Vendramin R, Spinazzi M, Laurette P, Fiers M, Wouters $\mathrm{J}$, et al. Melanoma addiction to the long non-coding RNA SAMMSON. PLoS Genet. 2016;531:518-22.

29. Strub T, Giuliano S, Ye T, Bonet C, Keime C, Kobi D, et al. Essential role of microphthalmia transcription factor for DNA replication, mitosis and genomic stability in melanoma. Oncogene. 2011;30:2319-32.

30. Ohanna M, Giuliano S, Bonet C, Imbert V, Hofman V, Zangari J, et al. Senescent cells develop a PARP-1 and nuclear factor\{kappa\}B-associated secretome (PNAS). Genes Dev. 2011;25:1245-61.

31. Coppe JP, Desprez PY, Krtolica A, Campisi J. The senescenceassociated secretory phenotype: the dark side of tumor suppression. Annu Rev Pathol. 2010;5:99-118.

32. Jelinek J, Liang S, Lu Y, He R, Ramagli LS, Shpall EJ, et al. Conserved DNA methylation patterns in healthy blood cells and extensive changes in leukemia measured by a new quantitative technique. Epigenetics. 2012;7:1368-78.

33. Ruzankina Y, Pinzon-Guzman C, Asare A, Ong T, Pontano L, Cotsarelis G, et al. Deletion of the developmentally essential gene ATR in adult mice leads to age-related phenotypes and stem cell loss. Cell Stem Cell. 2007;1:113-26.

34. Arantes-Rodrigues R, Henriques A, Pinto-Leite R, FaustinoRocha A, Pinho-Oliveira J, Teixeira-Guedes C, et al. The effects of repeated oral gavage on the health of male CD-1 mice. Lab Anim (NY). 2012;41:129-34.

35. Eichenbaum G, Damsch S, Looszova A, Vandenberghe J, Van den Bulck K, Roels K, et al. Impact of gavage dosing procedure 
and gastric content on adverse respiratory effects and mortality in rat toxicity studies. J Appl Toxicol. 2011;31:342-54.

36. Zhang JH, Chung TD, Oldenburg KR. A simple statistical parameter for use in evaluation and validation of high throughput screening assays. J Biomol Screen. 1999;4:67-73.

37. Bandyopadhyay D, Okan NA, Bales E, Nascimento L, Cole PA, Medrano EE. Down-regulation of p300/CBP histone acetyltransferase activates a senescence checkpoint in human melanocytes. Cancer Res. 2002;62:6231-9.

38. Sato S, Roberts K, Gambino G, Cook A, Kouzarides T, Goding CR. $\mathrm{CBP} / \mathrm{p} 300$ as a co-factor for the Microphthalmia transcription factor. Oncogene. 1997;14:3083-92.

39. Giuliano S, Cheli Y, Ohanna M, Bonet C, Beuret L, Bille K, et al. Microphthalmia-associated transcription factor controls the DNA damage response and a lineage-specific senescence program in melanomas. Cancer Res. 2010;70:3813-22.

40. Takahashi A, Ohtani N, Yamakoshi K, Iida S, Tahara $\mathrm{H}$, Nakayama K, et al. Mitogenic signalling and the p16INK4a-Rb pathway cooperate to enforce irreversible cellular senescence. Nat Cell Biol. 2006;8:1291-7.

41. Ha GH, Kim HS, Lee CG, Park HY, Kim EJ, Shin HJ, et al. Mitotic catastrophe is the predominant response to histone acetyltransferase depletion. Cell Death Differ. 2009;16:483-97.

42. Kuilman T, Michaloglou C, Mooi WJ, Peeper DS. The essence of senescence. Genes Dev. 2010;24:2463-79.

43. Dhomen N, Reis-Filho JS, da Rocha Dias S, Hayward R, Savage $\mathrm{K}$, Delmas V, et al. Oncogenic Braf induces melanocyte senescence and melanoma in mice. Cancer Cell. 2009;15:294-303.

44. Huang JM, Chikeka I, Hornyak TJ. Melanocytic nevi and the genetic and epigenetic control of oncogene-induced senescence. Dermatol Clin. 2017;35:85-93.

45. Cameron EE, Bachman KE, Myohanen S, Herman JG, Baylin SB. Synergy of demethylation and histone deacetylase inhibition in the re-expression of genes silenced in cancer. Nat Genet. 1999;21:103-7.

46. Sato T, Cesaroni M, Chung W, Panjarian S, Tran A, Madzo J, et al. Transcriptional selectivity of epigenetic therapy in cancer. Cancer Res. 2017;77:470-81.

47. Beeharry N, Rattner JB, Bellacosa A, Smith MR, Yen TJ. Dose dependent effects on cell cycle checkpoints and DNA repair by bendamustine. PLoS ONE. 2012;7:e40342.

48. Itahana K, Campisi J, Dimri GP. Methods to detect biomarkers of cellular senescence: the senescence-associated beta-galactosidase assay. Methods Mol Biol. 2007;371:21-31.
49. Tomayko MM, Reynolds CP. Determination of subcutaneous tumor size in athymic (nude) mice. Cancer Chemother Pharmacol. 1989;24:148-54.

50. Xu J, Cortellino S, Tricarico R, Chang WC, Scher G, Devarajan $\mathrm{K}$, et al. Thymine DNA Glycosylase (TDG) is involved in the pathogenesis of intestinal tumors with reduced APC expression. Oncotarget. 2017;8:89988-97.

51. Joshi S, Davidson G. TEAD transcription factors are required for normal primary myoblast differentiation in vitro and muscle regeneration in vivo. PLoS Genet. 2017;13:e1006600.

52. Kim D, Pertea G, Trapnell C, Pimentel H, Kelley R, Salzberg SL. TopHat2: accurate alignment of transcriptomes in the presence of insertions, deletions and gene fusions. Genome Biol. 2013;14: R36.

53. Langmead B, Salzberg SL. Fast gapped-read alignment with Bowtie 2. Nat Methods. 2012;9:357-9.

54. Love MI, Huber W, Anders S. Moderated estimation of fold change and dispersion for RNA-seq data with DESeq2. Genome Biol. 2014;15:550.

55. Benjamini Y, Hochberg Y. Controlling the false discovery rate: a practical and powerful approach to multiple testing. J R Stat Soc B. 1995;57:289-300.

56. Li H, Handsaker B, Wysoker A, Fennell T, Ruan J, Homer N, et al. The Sequence Alignment/Map format and SAMtools. Bioinformatics. 2009;25:2078-9.

57. Li H. A statistical framework for SNP calling, mutation discovery, association mapping and population genetical parameter estimation from sequencing data. Bioinformatics. 2011;27:2987-93.

58. Fitzgerald ME, Drohat AC. Coordinating the initial steps of base excision repair. Apurinic/apyrimidinic endonuclease 1 actively stimulates thymine DNA glycosylase by disrupting the product complex. J Biol Chem. 2008;283:32680-90.

59. Chong CR, Chen X, Shi L, Liu JO, Sullivan DJ Jr. A clinical drug library screen identifies astemizole as an antimalarial agent. Nat Chem Biol. 2006;2:415-6.

60. Petronzelli F, Riccio A, Markham GD, Seeholzer SH, Stoerker J, Genuardi M, et al. Biphasic kinetics of the human DNA repair protein MED1 (MBD4), a mismatch-specific DNA $N$-glycosylase. J Biol Chem. 2000;275:32422-9.

61. Turner DP, Cortellino S, Schupp JE, Caretti E, Loh T, Kinsella TJ, et al. The DNA N-glycosylase MED1 exhibits preference for halogenated pyrimidines and is involved in the cytotoxicity of 5iododeoxyuridine. Cancer Res. 2006;66:7686-93. 